\title{
The Components of Urban Growth in Developing Countries
}

\section{Prepared for the United Nations Population Division}

\author{
Guy Stecklov
}

5 May 2008 


\title{
Components of Urbanization Report
}

\author{
Contents
}

1. Introduction

2. Estimation Methodology and Data Availability
a. The Census Survival Ratio Method
b. Strengths and Weaknesses of the Census Survival Ratio Method
c. Examining Urban and Rural Fertility Assumptions
d. Examining Urban and Rural Mortality Assumptions
e. Data Availability

3. National and Urban Population Growth Trends

4. Components of Urban Growth
a. Overall Patterns in the Components of Urban Growth Over Time
b. Components of Urban Growth within each Continent
c. A Population-Weighted Approach to Estimating the Components of Urban Growth

5. Conclusion

6. References

7. Appendices 


\section{Introduction}

The shift in the residential pattern of the world's population has been a lengthy process. The roots of this process can be traced back as far as the development of settled agriculture in the $8000 \mathrm{BC}$, followed by a gradual and uneven uptake in the pace over the course of several millennia. During the industrial revolution, urbanization became a central element in the economic expansion and social reorganization of European as well as other states such as the U.S. One rough estimate places the share of the population in 1800 living in cities at about five percent (United Nations 1980). By the middle of the 20th Century, roughly 29 percent of the total world population was living in cities (United Nations 2007). The most recent estimates of the United Nations mark 2008 as the first year during which the majority of the world's population will be living in cities (United Nations 2007). This trend is expected to continue and current projections and 2008 marks both an important turning point but also the beginning of a new era where an increasingly large majority of the population will be urban. According to the latest projections, nearly 70 percent of the world's population is expected to be urban by the year 2050 (United Nations 2007).

This fundamental transition of the space inhabited by human populations - the urban transition marks an essential component of the broader demographic revolution that has helped to remake global and local population sizes and structures. By any account the past decades have been unique in terms of the rates of urban population growth occurring in the developing world (Preston 1979). Following from data from the World Urbanization Prospects, from 1950 when barely 17 percent of the populations of the countries in the developing world level were urban, by 2005 over $43 \%$ are now urban and that figure is predicted to reach 67 percent by 2050. These translate into current urban population growth rates in excess of 2.6 percent as well as past urban growth rates during the $1960 \mathrm{~s}$ and $1970 \mathrm{~s}$ that that are near or above four percent.

If current population predictions are correct, the world's overall population will reach by 9.2 billion by the year 2050. However, most of this growth is expected to occur in the urban sectors of the developing world. In fact, three quarters of the growth in the world's population between 1950 and 2050 will be attributed, according to projection, to growth in cities in the developing world. Anticipation of this process has generated intense interest in efforts to both control population movements within certain societies as well as efforts to assess the implications of rapid urban growth (Chen, Valente and Zlotnik 1998; Preston 1979). Results in both cases are decidedly mixed. In some states efforts have focused on controlling population movement from the rural sector in an effort to reduce urban population growth rates. At the same time, there is considerable interest in the underlying question of the extent to which urban growth rates are generated by rural to urban migration versus the extent to which they are the product of natural increase (Montgomery et al. 2003). The relevance of asking this question again is heightened not only by the passage of time but more so because of the fact that the data required to answer the question are becoming increasingly available, providing us with a broader and longer time series on the components of urban population growth.

This report is concerned with the question of what share of urban population growth is due to natural increase and what share is due to rural to urban migration flows. This question is particularly salient in developing countries, where more of the world's population growth is occurring and where urbanization trends are the fastest. This study revisits the issue of the driving mechanism for urban growth, aiming to assess the relative contribution of natural increase and rural to urban migration. This issue has been considered in two prior publications of the United Nations. The first provided both a broader discussion 
of urban and rural population growth more generally, as well as a presentation of the method for studying the components of urban growth using the Census Survival Ratio Method (United Nations 1980). The second report continued the analysis on the components to urban growth with the same basic methodology and using updated data from a larger number of countries (United Nations 2001).

The two prior reports have been instrumental in providing a gauge of the driving mechanisms behind urban population growth over the past half century and the present report builds on the methods developed in the two prior reports as well as the lessons learned from their analyses. The first report showed that nearly $2 / 3$ of urban population growth is due to natural increase. The second report showed a similar figure. The lesson taken from these first two rounds is that nearly $2 / 3$ of growth in cities is due to the continued impact of high rates of natural increase due to enduring differentials between fertility and mortality - differentials that continue to stimulate urban population growth in LDCs. The remaining roughly $1 / 3$ is due to net migration and reclassification - the latter - the effect of reclassification - is not possible to distinguish from the effect of net migration using this method. The results clearly defy the prevailing notion that urban growth is primarily driven by masses of rural to urban migrants. In fact, while rural to urban migration does accelerate urban population growth, in most countries it plays a far smaller role than natural increase.

The current study greatly expands the empirical range by including data on 248 censuses from 76 countries. We focus attention on certain specific assumptions underlying the methodology. In particular, we examine the methodological limitations to help to understand the extent to which the overall assessment of the components of growth may (or may not) be affected by these assumptions. These additional analyses provide further insight into the sensitivity of estimates of the components of urban growth.

\section{Estimation Methodology and Data Availability}

\section{a. The Census Survival Ratio Method}

The method used in this evaluation of the components of urban growth is based on a model developed by Sam Preston and used in both of the earlier UN reports on the components of urban growth (Preston 1979; United Nations 1980). The Census Survival Ratio Method (CSRM) is built on the use of repeated rounds of census data, which given the growing availability of census data from countries around the world including in developing countries, entails an important advantage in terms of the ability to reproduce this method over a broad range of countries and over repeated intervals of time. While census quality varies considerably from country to country, as well as over time, census estimates often provide the best if not only available enumeration of the population size and its basic characteristics in entirety.

The CSRM estimates are entirely based on figures drawn from census data and use the information to calculate the components of urban growth using a straightforward algorithm. The basic algorithm behind the CSRM operates under the assumption that the census data are correct and that they provide a reliable estimate of urban and rural population numbers at each of two points in time. Under a variety of assumptions which are discussed in detail below, census errors may lead to improper counts but will not necessarily generate biased estimates of the components of urban growth. This is an 
important advantage of this method, which would not necessarily be possible to achieve were we to rely on life tables estimates to calculate survivorship or use other seemingly more accurate methods to measure demographic behavior over the duration of the census intervals.

There are several steps in the process of estimating the components of urban growth. The first step involves a necessary adjustment due to the fact that the CSRM approach operates on population census counts that are precisely 10 years apart. Thus, population counts from each census must in most cases be shifted so that every pair of adjacent censuses are separated by exactly 10 years. This typically involves adjusting the population counts in each age group by shifting them forward (or backwards) in time based on the estimated exponential growth rate of the entire population measured over the same interval. This manipulation leads to the creation of two adjacent populations separated by exactly one decade, one at time $=\mathrm{t}$ and one at time $=\mathrm{t}+10$, divided into age groups, sex and urban and rural sectors.

The most fundamental assumption underlying the CSRM regards the estimation of survivorship for each age group for the population as a whole and then adjustment of the survivorship levels for urban and rural sectors. Initially, working with the entire population, we calculate cohort survival ratios based on the fraction of each age group at time $=\mathrm{t}$ that are alive at time $=\mathrm{t}+10$. The total cohort survival ratios for each age group $i$ for the country as a whole, $S(i)$, provides the backbone upon which the remaining estimates are based. In a later section, we examine more closely some of the potential implications of biases on our findings.

The next step in the process involves the use of the total cohort survival ratios to estimate separate survival ratios for the urban and rural sectors. If survival ratios are assumed to be similar across the two sectors, no adjustment is needed. However, if urban survival ratios are assumed to be greater than rural survival ratios - hence of the overall, national survival ratios - a method is needed to operationalize these differences. Both of the previous reports on the component of urban growth assumed that urban cohort survival ratios were 25 percent greater than rural survival ratios, while recognizing the arbitrariness of this assumption and examining the sensitivity of the results to variation in this value. We examine this assumption in further detail below and we also consider the implications of a refinement of the operationalization of this assumption in the methodology. Following an adjustment which is made to account for the relatively higher survival ratios in the urban relative to rural sectors, a set of age-specific urban cohort survival ratios are generated. These urban cohort survival ratios are used to predict the number of expected persons in each urban cohort $i$ at time $=\mathrm{t}+10$, $E U(i, t+10)$, based on the simple multiplication of the number in each cohort at time $=\mathrm{t}$ by the urban cohort survival ratio, $S^{U}(I)$. The gap between the expected size of the urban cohort $i$ at time $\mathrm{t}+10$, $E U(i, t+10)$, and the actual size of cohort $i$ at $\mathrm{t}+10, U(i, t+10)$, provides the estimate of rural to urban net migration combined with net reclassification over the given interval.

A more indirect approach is needed for estimating the number of child migrants because the children in the second census were born after the first census and their survival cannot be directly estimated in the same manner. The approach developed in the first report is to estimate the number of child migrants from the number of female rural to urban migrants multiplied by the estimated number of young children per woman migrant (United Nations 1980). Deriving the ratio of young children per woman migrant is generally not available, but might be estimated from the ratio of young children to 
women of reproductive age in the urban population. Of course, female levels of fertility vary considerably by age, as do age patterns of migrants. For this reason, it is suggested to weight both the female migrants and fertility by an appropriate proportionate age-specific fertility distribution. Then, the number of child migrants in the city is subtracted from the size of the population between the ages $0-10$ at time $\mathrm{t}+10$ to derive an estimate of urban growth that is due to natural increase and migration. We examine this assumption in more detail below.

Once the net migration and reclassification and natural increase estimates are derived for each cohort, the final step in the process is to calculate the proportion of total urban population growth which is due to net migration and classification from the ratio simple ratio of the two growth rates. Similarly, the estimated rate of natural increase from the urban population from our analysis is divided by the total urban population growth rate to provide us with the proportion of urban population growth that is due to urban natural increase. These two statistics are derived from our analysis and are the primary focus of our attention in the discussion of the results.

\section{b. Strengths and Weaknesses of the Census Survival Ratio Method}

The CSRM offers a consistent and transparent method for using data from two adjacent censuses, which provide estimates of the population stock in a country as a whole as well as more specifically in the urban and rural sectors, to generate flow estimates of migration including reclassification. Thus, the flow of migration over an interval is estimated without any data on either migration or population flows in general. This is a major advantage and enables estimation of rural to urban migration and urban natural increase wherever two censuses are available at about a decade apart.

The CSRM approach continues the approach of defining natural increase as the growth due to all current residents of the urban sector. This means that births of migrants after their arrival in cities and all future generations are all included in the natural increase component of growth. This is of course a definitional issue considered in earlier work with important implications (Rogers 1982). If the offspring of migrants are themselves considered migrants then almost all cities would be seen as entirely composed of migrants (Montgomery et al. 2003).

The most important criteria for an estimation method is whether or not it is able to produce estimates that are valid indicators of the true level of the process that is studied. From this perspective, our main concern is whether or not the CSRM is able to accurately assess the components of urban growth. Prior evidence for the strength of the approach are based on comparisons of the results from the CSRM approach to direct estimates of migration in Hungary where such data are available (United Nations 1980). Further evidence is available from a comparison of the estimated rate of natural increase for urban and rural sectors where birth and death data are classified by sector. In this case, the method is shown to approximate natural increase quite well including in developed countries where registration data are most reliable (United Nations 1980).

It is widely recognized, however, that the validity is difficult to gauge because the true value of net migration and natural increase over a given period is difficult to ascertain due to the inherent 
challenge of estimating separate urban and rural vital rates, even where data systems are of high quality. Ideally, were vital rates clearly measured and differentiated by urban and rural sector, census data collected with little or no under-enumeration or age-misstatement, international migration ignorable and urban classification remained unchanged over time, it would be straightforward to use a variation on the classic balancing equation in demography to calculate the components of urban growth. Of course, the real world is vastly different. In the real world, the CSRM may provide a reasonable second-best alternative for obtaining a measure of the role of natural increase and net migration and reclassification for urban growth. This is because the CSRM appears less sensitive to various types of data errors that are pervasive in official population statistics. The manner in which the calculations are carried out generate a tendency towards balancing of errors overall, particularly if errors such as international migration or under-enumeration are serious but consistent in their magnitude over time. In contrast, if we were to estimate survival using mortality statistics, the method may end up creating more bias in the results.

Nonetheless, it is important to consider how differences between the population sizes in both the urban and rural areas of the country across censuses might result from factors which are difficult if not impossible to measure. Such factors, which clearly are incorporated in all census estimates to one degree or another, may affect estimates of the role of rural to urban migration and natural increase in total urban population growth. This includes the impact of international migrants, as well as changing levels of census undercount, census age misstatement, and urban reclassification where urban boundaries are shifted over time. Each of these phenomena will have implications for the accuracy of the methodology that is employed and we considered them in some detail in the next sections.

In fact, the total cohort survival ratios include both mortality as well as any number of factors which might affect the count of persons in each age group measured during either the first or the second census for each interval. The most obvious factor that is incorporated in the estimate of the survival ratio is net international migration. For age groups that tend to send out net international migrants over this period, the estimated values of cohort survival, S(i), will be under-estimated because international outmigrants are indistinguishable from deaths to cohort members. On the other hand, where age groups tend to expand because of net in-migration over the period, the values of S(i) will be over-estimated. However, net international migration is only one of several factors which may affect our estimated cohort survival ratios. Another critical factor is the accuracy of census enumeration. When census enumeration improves over time with reduced undercounts, there will be a tendency for cohort survival ratios to be over-stated, and vice-versa. Also, census age misstatement is another potential source of bias since age misstatement is often systematic.

Political rezoning or reclassification of geographic boundaries within a state is another serious concern because the CSRM approach does not distinguish between net migration and reclassification. Whether individuals move to cross "urban" borders or whether borders are shifted to include more people makes no difference to this model. Of course, there are clearly different implications in terms of mobility when city growth is due to physical displacement or because of redrawn boundaries. Separating reclassification from rural to urban migration requires specific data not usually available, but an application of decomposition methods to data from the Philippines highlights the potential importance of reclassification to total urban growth (Pernia 1976). Elsewhere, a study on the components of urban 
growth using data from Thailand shows that over one-third of estimated net migration to cities was due to urban reclassification (Pejaranonda, Santipaporn and Guest 1995). Thus, in some contexts, reclassification may in fact be the primary cause of urban growth. When statistical definitions are revised in large countries, such as China, even global statistics can be seriously affected and this means that interpretations need to be sensitive to definitional issues (Goldstein 1990). In this and prior studies on the components of urban growth, net migration then includes reclassification - whether this point is made explicit or not.

Finally, while it is important to understand the underlying factors that might affect our estimates of the total cohort survival ratios, it is important to note that as long as the biases are consistent across two censuses, then there will be little or no overall impact on our findings. This is an important advantage that underlies the CSRM approach and which has may not yet have been made explicit. Because several of the types of errors such as under-enumeration or age bias may well be consistent from census to census, the findings from the CSRM will end up considerably more robust than what would be otherwise expected and should have relatively little impact on estimates of the components of urban growth.

\section{c. Examining Urban and Rural Fertility Assumptions}

The CSRM relies on the census estimates of populations in age groups observed in two different censuses. However, estimating the number of child migrants between the first and second census is a particular challenge because the same children were not yet born at the time of the first census. The process proposed in the CSRM approach is to estimate the number of migrant children into the initial age interval based on the number of female migrants during the period and the average distribution of childbearing by age. The calculation requires that the total number of children of both sexes in age category $1, U_{T}(1,2)$, in the urban sector from the second census be multiplied by a fraction denoting the proportion of childbearing from migrant women. More formally, this is written using the original notation, where the first term on the right-hand-side refers to number of female migrants age $i, N M_{F}(i)$, divided by the size of the female urban population at time $2, U_{F}(i, 2)$, and $F(i)$ refers to the proportional age distribution of fertility,

$$
N M(1)=\frac{\sum N M_{F}(i) * F(i)}{\sum U_{F}(i, 2) * F(i)} * U_{T}(1,2)
$$

Since both the number of female migrants and the number of women in the urban sector at time 2 are multiplied by the same set of factors, $F(i)$, the absolute level of fertility cancels out and does not play a role. However, there are two issues to examine. One involves a basic decision regarding whether the set of age specific rates should be used for migrants that is different from the national level. The other concern is whether or not the specific rates used in prior reports should be continued or whether a set or a variety of sets of updated rates should be used.

The answer to the first question is not straightforward and relies on a review of the state of the evidence in the literature. In fact, the literature shows no clear decision over whether rural-to-urban migration itself leads to fertility decline or whether some of the observed associations are explained by migrant selectivity (Jensen and Ahlburg 2004; Montgomery et al. 2003; White, Moreno and Guo 1995). 
For our purposes, the implications would be that if city-bound migrants are selected for lower fertility, their five-year fertility rates following migration should be similar to those already living in the city (Chattopadhyay, White and Debpuur 2006; White et al. 2005). Alternatively, if lower migrant fertility is mainly driven by assimilation, which occurs over time, and disruptions associated with the move alongside a possible rebound following their arrival might imply that their fertility levels should be closer to the higher rural rates (Jensen and Ahlburg 2004). Lacking conclusive evidence on this matter, no single approach is entirely defensible. We opt for simplicity and transparency, and choose to adopt average country-level proportional age specific fertility rates, similar to the approach used in the two earlier studies on the components of urban population growth rather than to differentiate fertility patterns between urban and rural sectors (United Nations 1980, 2001).

The second, related point of concern is whether the results will depend on the specific set of national $F(i)$ which are used, and if so how should one or a series of such sets of rates be chosen. Clearly, the immediate impact of choosing a fertility age schedule only has implications for the number of migrants in the first age group, so the overall migration rate will not be dramatically altered.

However, due to the relatively strong association between the peak ages of migration and childbearing, the impact will be non-trivial. Migration probabilities tend to peak during the young adult years - like childbearing patterns. The correlations between these two patterns will increase the impact of changing the age pattern of childbearing on the number of child migrants. We explore these implications by examining various sets of $F(i)$ and studying the impact of shifting the $F(i)$ on our findings.

In Figure 1 we show the age pattern of fertility used in the two prior rounds of the components of migration study, labeled "Original", along with several alternative distributions drawn from the United Nations database on age-fertility schedules and then normalized. The original distribution is clearly the oldest age pattern, with the mean age estimated at 32.0, and with only 19 percent of childbearing occurring under age 25 , while the youngest is for the set of age patterns for TFRs under 2.0, where the mean age is a 26.7 and 41 percent of childbearing occurs before age 25 . Between the extremes of the under two distribution and the original distribution lie the patterns for TFRs between 2-5, 5-7, and over 7. The "Original" pattern along with the $\mathrm{TFR}<2$ pattern appear to be unusual whereas the remaining patterns all lie substantially closer together as evidenced by their similar mean ages: $28.2,29.4$, and 29.7 moving from the TFR category of 2-5 children, to 5-7 children and then to the TFR $>7$ category. 
Figure 1: Proportional Age Specific Fertility Rates from the United Nations Database for countries from 1950-2000 from prior, "original" analysis on the Components of Urban Growth

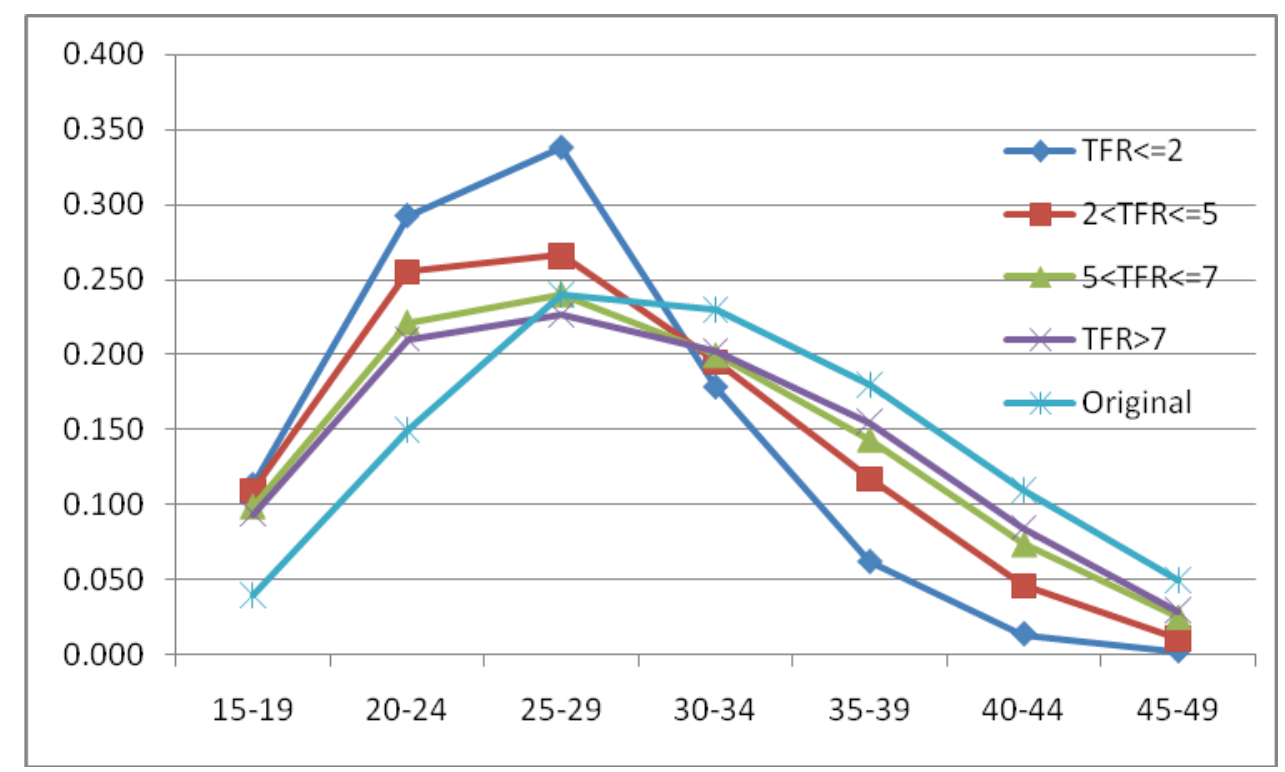

Not only does the original age pattern stand out in Figure 1, but its impact on the number of estimated child migrants also appears as a clear "outlier." In Figure 2 the estimated number of child migrants in Mexico is shown under several scenarios where the age distribution of childbearing is varied across each scenario. The results of Figure 2 highlight the fact that the number of child migrants from the "original" age pattern of fertility is substantially less than what is generated from any of the four other choices. In fact, there is considerably less variation among the United Nations generated fertility age patterns than there is between the United Nations patterns and the "Original" age pattern. 
Figure 2: An Illustration of the Impact of Varying the Age Pattern of Fertility on the Estimated Number of Child Migrants in Each Time Period, Mexico from the 1960s-1980s.

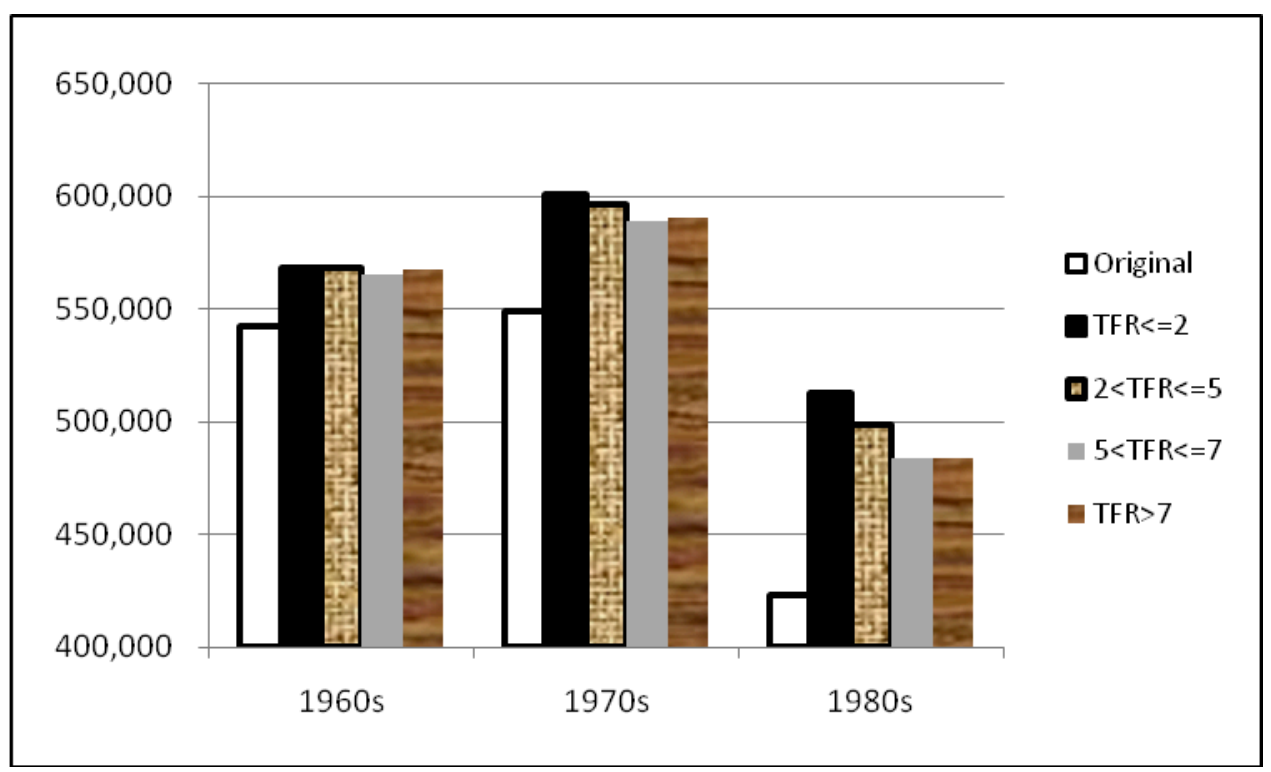

Because the original age distribution pattern generates estimates that appear inconsistent with several appropriate alternative patterns, and given that most countries in our sample are clearly in the midst of fertility transition, we adopt the estimates for the middle range of TFR levels - between 2 and 5 children (see estimates below in bold in Table 1). It is worthwhile noting, however, that the results we obtain are very insensitive to the choice of a fertility-age distribution. All the alternatives generate higher estimates of the number of child higher than those generated by the original age pattern. This means that the estimated pattern we employ is going to generate larger estimates - albeit by a small margin - of the number of rural to urban migrants and at the same time it will lead us to predict a larger than before role for rural to urban migration as the factor driving urban growth. Thus, if the "true" profile is actually more like the original age pattern, our choice of a "younger" age pattern of fertility for the analysis of the components of urban growth will generate a downwards biased estimate of the role of natural increase relative to what would otherwise be obtained.

Table 1: Proportional Age Specific Fertility Rates from the UN Database for countries from 19502000 from Original Analysis of the Components of Urban Growth

\begin{tabular}{cccccc} 
& Original & TFR $<=\mathbf{2}$ & $\mathbf{2}<$ TFR $<=\mathbf{5}$ & $\mathbf{5}<\mathbf{T F R}<=\mathbf{7}$ & $\mathbf{T F R}>\mathbf{7}$ \\
\hline $\mathbf{1 5 - 1 9}$ & 0.04 & 0.11 & $\mathbf{0 . 1 1}$ & 0.10 & 0.09 \\
$\mathbf{2 0 - 2 4}$ & 0.15 & 0.29 & $\mathbf{0 . 2 6}$ & 0.22 & 0.21 \\
$\mathbf{2 5 - 2 9}$ & 0.24 & 0.34 & $\mathbf{0 . 2 7}$ & 0.24 & 0.23 \\
$\mathbf{3 0 - 3 4}$ & 0.23 & 0.18 & $\mathbf{0 . 2 0}$ & 0.20 & 0.20 \\
$\mathbf{3 5 - 3 9}$ & 0.18 & 0.06 & $\mathbf{0 . 1 2}$ & 0.14 & 0.15 \\
$\mathbf{4 0 - 4 4}$ & 0.11 & 0.01 & $\mathbf{0 . 0 5}$ & 0.07 & 0.08 \\
$\mathbf{4 5 - 4 9}$ & 0.05 & 0.00 & $\mathbf{0 . 0 1}$ & 0.02 & 0.03 \\
\hline Mean Age & 32.0 & 26.7 & 28.2 & 29.4 & 29.9
\end{tabular}




\section{d. Examining Urban and Rural Mortality Assumptions}

We make two revisions to the existing methodology that was used in the prior two reports on the components of urbanization, and we explain the rationale in this section. If urban and rural survival ratios are similar, the total cohort survival rate, $S$, could used in both sectors and it would be relatively straightforward to derive the expected urban cohort size at each census. However, there is considerable evidence to suggest that urban survival is generally higher than rural survival, except in special settings and for some particular age groups (Montgomery et al. 2003). Thus, the method of calculation of urban survival ratios in the two prior United Nations reports using the CSRM approach built on the fact that the total cohort survival rate offers a good baseline and then an adjustment can be made to lower the urban survival rate relative to rural and total survival ratios. In both cases, rural mortality probabilities were assumed to be 25 percent higher than urban. This calculation followed from analyses conducted in both reports, which broadly supported one another, and which showed the " 25 percent" figure to be a reasonable if "back-of-the-envelope" calculation. Given the paucity of quality data to precisely estimate this case and given the variability in the expected proportions across countries, using an across-theboard 25 percent differential has appeared to offer a reasonable, transparent solution.

Yet, while the 25 percent differential between urban and rural survival appears reasonable, issues arise because of the possibility that values of $S(i)$ may in fact exceed unity. This could occur for a variety of reasons. For example, survival ratios may exceed unity if the difference between the number of international migrants arriving in a country in age group $i$ and the number of migrants leaving the country is larger than the number of deaths during the same period. Alternatively, survival ratios may exceed one if there is an improvement in census enumeration which leads to an increase in the cohort "survival" because the level of under-enumeration for a cohort declines between two consecutive censuses. Survival ratios may even exceed one where cohorts enter into ages or exit from ages with high levels of age mis-statement or exaggeration. In fact, it turns out that survival ratios frequently exceed one in the data - an issue we directly examine below - and for many countries nearly half of all cohort survival ratios fall into this category.

The consequences of this adjustment are clear. Were urban and rural survival ratios maintained at the same level, the expected urban population at the end of an interval would be lower and the net migration and reclassification would comprise a larger fraction of total urban growth over the interval. As cohort survival ratios larger than one are one signal for real factors such as international migration which may or may not be distributed proportionately across urban and rural areas as well as data problems due to under-enumeration and age-misstatement, it is not obvious how these situations should be treated. However, these issues and their implications are analyzed in greater detail below.

The strategy we adopt in this report is to assume that urban and rural survival ratios are equalized whenever total survival ratios reach one. The expectation is that as societies develop and survival ratios improve health care access tends to improve. These and other factors tend to reduce the rural-urban survival differential (Montgomery et al. 2003). Any constant proportional difference between urban and rural survival will become increasingly marginal as overall survivorship approaches unity. However, once survivorship exceeds unity, a constant proportional difference will begin to generate increasingly large gaps between rural and urban populations and this will lead to a reverse effect where the ruralurban health gap increases again as survivorship rises above unity. Finally, it is important to note that this variation in the methodology which we have enacted in this analysis - as in the case of the methodological adjustment of the age-pattern of fertility -will lead us to over-estimate the proportion of 
urban growth that is due to net rural to urban migration (and reclassification) and to under-estimate the proportion that is due to natural increase.

\section{e. Data Availability}

Countries use census data for a variety of purposes - from political redistricting and identifying tax bases to gaining an understanding of the changing characteristics of their populations. Censuses require considerable resources and organization. As countries develop censuses become more feasible and common. Over the years, there has been a vast expansion of census taking across the globe and this has provided the vital resource for this project and for this new round of analysis. In comparison to the prior rounds, this current revision offers both a broader representation of developing countries as well as a longer temporal perspective on trends in each of the countries as well as for regions as a whole. This combination of more censuses from more countries greatly increases the value of this endeavor, which is aimed at understanding the components of growth in developing countries, and now can do so using an impressive collection of census files.

In Table 2, the list of countries and censuses by region are shown that are included in our analysis and findings. In all, this report is based on a total of 248 separate census files -87 more than the number used in the last report. There are a total of 76 countries in the three regions in comparison to 55 that are included in the prior, most recent version of this report (United Nations 2001). The largest number of countries is in Africa (28) and the largest increase in representation is in both sub-Saharan Africa and Western Asia. In the prior report, 12 countries from sub-Saharan Africa provided data on at least one interval. In the present report, 23 countries from Sub-Saharan Africa are included. Also, following the break-up of the ex-Soviet Union, several new countries that have never been included before are now incorporated into our analysis for the 1980s and 1990s.

As explained earlier, the method of analysis works on estimating migration flows over the course of a decade. For that reason, decades are the temporal unit of analysis, even when censuses do not fit this exact pattern. We define a series of decades from the 1950s through the 1990s. For each country, the year of the census which is used for each interval is shown. It is readily apparent that the decade of the 1980s provides the greatest number of census intervals for our analysis. It may well be that the 1990s will be more present in a future version of this report because the lag between when the census is carried out and the data is provided to the United Nations complicates any assessment of a trend in the census availability for now (Cohen 2004). At the same time, we have only 5 estimates for the 1950s, which leads us to ignore this interval in our subsequent analyses focusing on temporal trends.

There are two additional issues that require consideration. The first and more central consideration is that census intervals required for the CSRM approach should span decadal intervals perfectly but the actual intervals are almost always a bit longer and occasionally shorter than 10 years. The procedure in this case is to shift up the date of the first census by adjusting the population counts so that perfect decades are formed in order to apply the method. Once a census interval becomes considerably longer than a single decade, and overlaps two decades, we essentially create duplicate decadal estimates for each of the decadal intervals. This is the same approach used in the prior United Nations report. In this round, due to the expansion of data, this happens rather frequently and we have 
14 cases where the interval appears twice because the interval is much longer than 10 years. Once a census interval extends beyond our 23 year limit, the CSRM approach is not applied and the interval is ignored. This is because there is a serious cost in terms of accuracy when interpolating age-specific populations for such a long period.

A second consideration concerns where exactly is the actual census interval positioned for descriptive and analytical purposes. While census intervals are defined by two consecutive census files, the intervals do not all begin and end when decades begin and end. In fact, many censuses occur in middecades rather than on the starting year of a decade such as 1990 or 2000 . In that case, when we categorize intervals into respective blocks of time, we place census intervals in the interval which overlaps for more years with the appropriate decade. Where this conflicts with the positioning used in the prior United Nations report, we tend to give preference to replicability in those rare circumstances.

There are also several countries and censuses missing from Table 2 because they are not used in this analysis. We tried to maintain a consistent set of rules for inclusion. The principle criteria are developing countries with at least two censuses taking place within a 23 year interval. However, in some cases the data itself was used to exclude countries. In particular, we tried to avoid censuses where there were dramatic shifts across intervals in the estimates of the migration rates. Shifts for example from large positive to large negative values were seen as likely indicators of large scale problems that this methodology is not appropriate for handling. Overall, the CSRM method is not likely to be as accurate in contexts where there is dramatic variation in migration levels over census intervals. While these trends may be real, this decision did lead to some reduction in the final sample size.

Table 2: Census Data Used in the Estimation of the Components of Urban Growth for Each Decade

\begin{tabular}{|c|c|c|c|c|c|c|c|c|c|c|c|c|}
\hline \multirow[b]{2}{*}{ Africa } & \multirow[b]{2}{*}{ Eastern Africa } & \multirow[b]{2}{*}{ Ethiopia } & \multicolumn{2}{|c|}{ 1950's } & \multicolumn{2}{|c|}{ 1960's } & \multicolumn{2}{|c|}{ 1970's } & \multicolumn{2}{|c|}{ 1980's } & \multicolumn{2}{|c|}{ 1990's } \\
\hline & & & & & & & & & 1984 & 1994 & & \\
\hline & & Kenya & & & & & 1969 & 1979 & 1979 & 1989 & & \\
\hline & & Madagascar & & & & & & & 1975 & 1993 & & \\
\hline & & Mauritius & & & & & 1972 & 1983 & 1983 & 2000 & 1983 & 2000 \\
\hline & & Rwanda & & & & & & & 1978 & 1991 & 1991 & 2002 \\
\hline & & Uganda & & & & & 1969 & 1991 & 1969 & 1991 & 1991 & 2002 \\
\hline & & Tanzania & & & & & 1967 & 1978 & 1978 & 1988 & & \\
\hline & & Zambia & & & & & 1974 & 1980 & 1980 & 1990 & & \\
\hline & & Zimbabwe & & & & & 1969 & 1982 & 1982 & 1992 & & \\
\hline & Northern Africa & Egypt & & & 1960 & 1976 & 1960 & 1976 & 1976 & 1986 & 1986 & 1996 \\
\hline & & Libya & & & 1964 & 1973 & 1973 & 1984 & & & & \\
\hline & & Morocco & & & 1960 & 1971 & 1971 & 1982 & 1982 & 1994 & 1994 & 2004 \\
\hline & & Sudan & & & & & 1973 & 1983 & & & & \\
\hline & & Tunisia & & & 1966 & 1975 & 1975 & 1984 & 1984 & 1994 & & \\
\hline & Southern Africa & Botswana & & & 1964 & 1971 & 1971 & 1981 & 1981 & 1991 & & \\
\hline & & Namibia & & & & & & & & & 1991 & 2001 \\
\hline & & South Africa & 1951 & 1960 & 1960 & 1970 & 1970 & 1996 & 1970 & 1996 & & \\
\hline & & Swaziland & & & & & & & & & 1986 & 1997 \\
\hline & Western Africa & Benin & & & & & & & & & 1992 & 2002 \\
\hline & & Burkina Faso & & & & & & & 1975 & 1985 & & \\
\hline & & Cape Verde & & & & & & & & & 1990 & 2000 \\
\hline
\end{tabular}




\begin{tabular}{|c|c|c|c|c|c|c|c|c|c|c|c|c|}
\hline & & Cote d'Ivoire & & & & & & & 1975 & 1988 & & \\
\hline & & Ghana & & & 1960 & 1970 & 1970 & 1984 & 1984 & 2000 & 1984 & 2000 \\
\hline & & Liberia & & & & & 1974 & 1984 & & & & \\
\hline & & Mali & & & & & & & 1976 & 1987 & & \\
\hline & & Niger & & & & & & & 1977 & 1988 & 1988 & 2001 \\
\hline & & Senegal & & & & & & & 1976 & 1988 & & \\
\hline & & Togo & & & 1959 & 1970 & & & & & & \\
\hline & Central Africa & Cameroon & & & & & & & 1976 & 1987 & & \\
\hline Asia & Eastern Asia & China & & & & & & & 1982 & 1990 & 1990 & 2000 \\
\hline & & Republic of Korea & & & 1960 & 1970 & 1970 & 1980 & 1980 & 1990 & 1990 & 2000 \\
\hline & South-Eastern Asia & Indonesia & & & 1961 & 1971 & 1971 & 1980 & 1980 & 1990 & 1990 & 2000 \\
\hline & & Malaysia & & & & & 1970 & 1980 & 1980 & 1991 & 1991 & 2000 \\
\hline & & Myanmar & & & & & 1973 & 1983 & & & & \\
\hline & & Philippines & & & & & 1970 & 1980 & 1980 & 1990 & & \\
\hline & & Thailand & & & & & 1970 & 1980 & 1980 & 1990 & 1990 & 2000 \\
\hline & Western Asia & Armenia & & & & & & & 1979 & 1989 & 1989 & 2001 \\
\hline & & Georgia & & & & & & & 1979 & 1989 & & \\
\hline & & Iraq & & & 1957 & 1965 & 1965 & 1977 & 1977 & 1987 & & \\
\hline & & Israel & & & & & 1972 & 1983 & 1983 & 1995 & & \\
\hline & & Jordan & & & 1961 & 1979 & 1961 & 1979 & 1979 & 1994 & & \\
\hline & & Syria & & & 1960 & 1970 & 1970 & 1981 & 1981 & 1994 & & \\
\hline & & Turkey & & & 1960 & 1970 & 1970 & 1980 & 1980 & 2000 & 1980 & 2000 \\
\hline & South-Central Asia & Bangladesh & & & 1961 & 1974 & 1974 & 1981 & 1981 & 1991 & & \\
\hline & & India & & & 1961 & 1971 & 1971 & 1981 & 1981 & 1991 & 1991 & 2001 \\
\hline & & Iran & & & & & 1966 & 1976 & 1976 & 1986 & & \\
\hline & & Kazakhstan & & & & & & & 1979 & 1989 & 1989 & 1999 \\
\hline & & Kyrgyzstan & & & & & & & 1979 & 1989 & & \\
\hline & & Maldives & & & & & 1977 & 1985 & 1985 & 1990 & 1990 & 1995 \\
\hline & & Nepal & & & 1961 & 1971 & 1971 & 1981 & 1981 & 1991 & & \\
\hline & & Pakistan & & & & & 1972 & 1981 & 1981 & 1998 & 1981 & 1998 \\
\hline & & Sri Lanka & & & 1963 & 1971 & & & & & & \\
\hline & & Tajikistan & & & & & & & 1979 & 1989 & & \\
\hline & & Uzbekistan & & & & & & & 1979 & 1989 & & \\
\hline LAC & Central America anc & aribbean & & & & & & & & & & \\
\hline & & Costa Rica & & & 1963 & 1973 & 1973 & 1984 & & & & \\
\hline & & Cuba & 1953 & 1970 & 1953 & 1970 & 1970 & 1981 & & & & \\
\hline & & Dominican Republic & 1950 & 1960 & 1960 & 1970 & 1970 & 1981 & & & 1993 & 2002 \\
\hline & & El Salvador & & & 1961 & 1971 & 1971 & 1992 & 1971 & 1992 & & \\
\hline & & Guatemala & 1950 & 1964 & 1964 & 1973 & & & & & & \\
\hline & & Haiti & 1950 & 1971 & 1950 & 1971 & 1971 & 1982 & & & & \\
\hline & & Honduras & & & 1961 & 1974 & 1974 & 1988 & 1974 & 1988 & & \\
\hline & & Jamaica & & & 1960 & 1982 & 1960 & 1982 & 1982 & 1991 & 1991 & 2001 \\
\hline & & Mexico & & & 1960 & 1970 & 1970 & 1980 & 1980 & 1990 & 1990 & 2000 \\
\hline & & Nicaragua & & & 1963 & 1971 & & & & & & \\
\hline & & Panama & & & 1960 & 1970 & 1970 & 1980 & 1980 & 1990 & & \\
\hline & & Puerto Rico & & & 1960 & 1970 & 1970 & 1980 & 1980 & 1990 & & \\
\hline & South America & Argentina & & & 1960 & 1980 & 1960 & 1980 & 1980 & 1991 & & \\
\hline & & Bolivia & & & & & & & 1976 & 1992 & & \\
\hline & & Brazil & & & 1960 & 1970 & 1970 & 1980 & 1980 & 1991 & 1991 & 2000 \\
\hline & & Chile & & & 1960 & 1970 & 1970 & 1982 & 1982 & 1992 & 1992 & 2002 \\
\hline & & Colombia & 1950 & 1964 & 1964 & 1973 & & & 1985 & 1993 & & \\
\hline
\end{tabular}




\begin{tabular}{l|l|ll|ll|ll|ll|} 
Ecuador & 1962 & 1974 & 1974 & 1982 & 1982 & 1990 & 1990 & 2001 \\
Paraguay & & 1962 & 1972 & 1972 & 1982 & 1982 & 1992 & 1992 & 2002 \\
Peru & & 1961 & 1972 & 1972 & 1981 & 1981 & 1993 & & \\
Uruguay & 1963 & 1975 & 1975 & 1985 & & & 1985 & 1996 \\
Venezuela & & 1961 & 1971 & 1971 & 1981 & 1981 & 1990 & & \\
\hline
\end{tabular}

Note: Figures in Italics refer to censuses that span more than one decade.

It is obvious from Table 2 that there is considerable variation in the frequency with which countries appear in the data. Some countries, such as Morocco, Republic of Korea, and India appear four times in our analysis whereas many more countries only appear in one or two intervals. Even among some of those that appear more than once, in several cases the number of appearances is due to the fact that their census intervals span more than one interval. Out of the total 76 countries that appear at least once in the table, and ignoring entries that are replicated because the intervals span two decades, there are no countries with 5 observations, 10 with four intervals, 20 with three, 24 with two, and 22 with one. The value of identifying the number of appearances of each country is that it enables us to be sensitive to situations where any estimated trends over time for a region or all regions combined is heavily influenced by individual countries which enter and exit repeatedly over the course of time. Thus, temporal trends may be driven as much by shifting compositions of countries as by changing patterns of urbanization for those countries that are observed. This problem is now more meaningful than in earlier iterations of this report because the number of intervals has grown sufficiently to raise the utility of examining inter-temporal trends.

Our strategy for treating the problem of country heterogeneity in any temporal analyses is to replicate many of the analyses but using a subsample of countries where there are at least three census intervals. There are 30 such countries ( 36 counting the replicated decades). The advantage of maintaining a relatively consistent composition of countries in the data analysis is that we can be more confident that the findings reflect a real shift in census patterns and not a shift in the country composition. Of course, we could also limit this to countries that appear in every interval, but that would severely reduce our sample size to only 10 countries.

\section{National and Urban Population Growth Trends}

In this section we begin to examine the empirical estimates of urbanization obtained from the application of the CSRM approach to the United Nations database on censuses. The countries in our analysis are all formally defined by the United Nations as developing countries, although there are wide gaps separating their development-related indicators. Due to the fact that individual countries as well as regions differ in terms of their levels of development, their population growth rates as well as their levels of urbanization are distinctly different as are the estimated rates at which they are urbanizing.

The results displayed in Table 3 show that for the group of countries as a whole across the entire period, the average population growth rate is 2.4 percent per year. However, this growth rate has been steadily declining over time across the entire sample from between 2.6-2.7 percent in the 1950s and $1960 \mathrm{~s}$ to 2.4 in the $1980 \mathrm{~s}$ and 1.8 in the 1990s. On the other hand, the percentage urban, which stands at 39 percent overall, has risen for all regions from under 36 percent prior to the 1970 s to 40 percent in the 
1980s and almost 44 percent in the 1990s. Similarly, we note an impressive decline in the rate of urbanization, which stood as high as 2.2 percent in the 1960s and fell to 1.5 percent in the 1980s and 1.4 percent in the 1990s.

Table 3: Regional and Total Estimates of Annual Rate of Population Growth, Percentage Urban and Annual Rate of Urbanization, 1950s-1990s (All countries included).

\begin{tabular}{cccccccc} 
& & \multicolumn{7}{c}{ Year } \\
Continent & & $\mathbf{1 9 5 0 ' s}$ & $\mathbf{1 9 6 0 ' s}$ & $\mathbf{1 9 7 0 ' s}$ & $\mathbf{1 9 8 0}$ 's & $\mathbf{1 9 9 0 ' s}$ & Total \\
\hline \multirow{3}{*}{ Africa } & Pop Growth Rate (\%) & 2.50 & 2.56 & 3.02 & 2.69 & 2.38 & 2.69 \\
& Percent Urban & 42.59 & 26.84 & 28.99 & 25.71 & 30.07 & 27.91 \\
& Rate of Urbanization (\%) & 0.99 & 4.36 & 2.34 & 2.09 & 1.71 & 2.39 \\
\multirow{4}{*}{ Asia } & Pop Growth Rate (\%) & & 2.69 & 2.74 & 2.39 & 1.36 & 2.35 \\
& Percent Urban & & 24.27 & 31.95 & 40.27 & 40.97 & 35.46 \\
& Rate of Urbanization (\%) & & 2.25 & 2.29 & 1.36 & 1.57 & 1.80 \\
& Pop Growth Rate (\%) & 2.70 & 2.48 & 2.13 & 2.03 & 1.57 & 2.19 \\
& Lercent Urban & 31.50 & 44.93 & 51.38 & 58.74 & 66.15 & 51.29 \\
& Rate of Urbanization (\%) & 1.84 & 1.40 & 1.22 & 0.92 & 0.74 & 1.20 \\
\hline \multirow{3}{*}{ Total } & Pop Growth Rate (\%) & 2.67 & 2.55 & 2.60 & 2.41 & 1.79 & 2.40 \\
& Percent Urban & 33.35 & 35.92 & 38.06 & 39.79 & 43.69 & 38.92 \\
& Rate of Urbanization (\%) & 1.70 & 2.23 & 1.92 & 1.51 & 1.40 & 1.76 \\
\hline & & & & & & &
\end{tabular}

Regional differences in all three measures are readily apparent in the results. Population growth rates are highest in Africa when averaged over the all periods, but this ranking is not constant over time. In the 1960s as the population growth rates differed little across the three regions. According to Table 3, Asia's population growth rates were highest at 2.7 percent whereas Africa was second at 2.6 percent and LAC lowest at 2.5 percent. This ranking varies little depending on whether we include all countries or just countries that are consistently present in our file to reduce the effects of shifting country composition on changes in the average growth levels over time. Regardless of whether all country estimates are included or only the limited subset of countries with at least three intervals, the temporal trends are clear and insensitive to the effects of country composition. However, as the fertility transition progresses in most areas faster than in Africa, Africa in the 1990s has the highest population growth rate, at 2.4 percent whereas population growth rates in LAC reach 1.6 percent and in Asia they fall to 1.4 percent.

Levels of urbanization also vary quite dramatically over time. On average across all time intervals, urbanization levels are highest in Latin America and the Caribbean (51 percent) while they are lowest in Africa (28 percent) and Asia lies in between (35 percent). Putting aside the 1950s, urbanization levels in Africa are not only the lowest but the change in levels of urbanization are also the smallest between the 1960s and the 1990s. In Asia, urbanization levels also began at an even lower 24 percent in the 1960s, but increased to 41 percent by the 1990s. In contrast, urbanization levels in LAC begin in the 1960s at the highest level among the three regions (45 percent) and continue to climb considerably reaching 66 percent by the 1990s - the highest among all regions. Yet, despite the regional diversity in urbanization level and trends, one consistent finding is that the process of urbanization appears to be progressing in all regions over time as is to be expected over the course of the demographic transition. 
Figure 3 illustrates the relationship between the percent urban in each country at each point in time and the rate of urbanization. Most countries tend to lie between 20-60 percent urbanization and the rate of urbanization is in most cases between 0-3 percent per year. Also, as already noted in the prior report on urbanization (United Nations 19xx) and as to be expected from a logistic type process, rates of urbanization progressively decline as countries reach higher levels of urbanization. The figure below illustrates both the clear decline in the level and variability in the rate of urbanization as the proportion urban rises above 0.6. In the figure below, we plot a series of lines fitted using nonparametric methods to each decade's data in order to compare the pattern across decades. What is most impressive from this figure is the similar pattern exhibited over all decades. There is some variability in the rate of urbanization seen over time for countries at low levels of urbanization, although most of this observed variation is due to the 1990 decadal estimates which are substantially lower but also based on relatively few cases. Otherwise, once urbanization levels exceed 40 percent the relationship between urbanization levels and urbanization rates appears very stable over time.

\section{Figure 3}

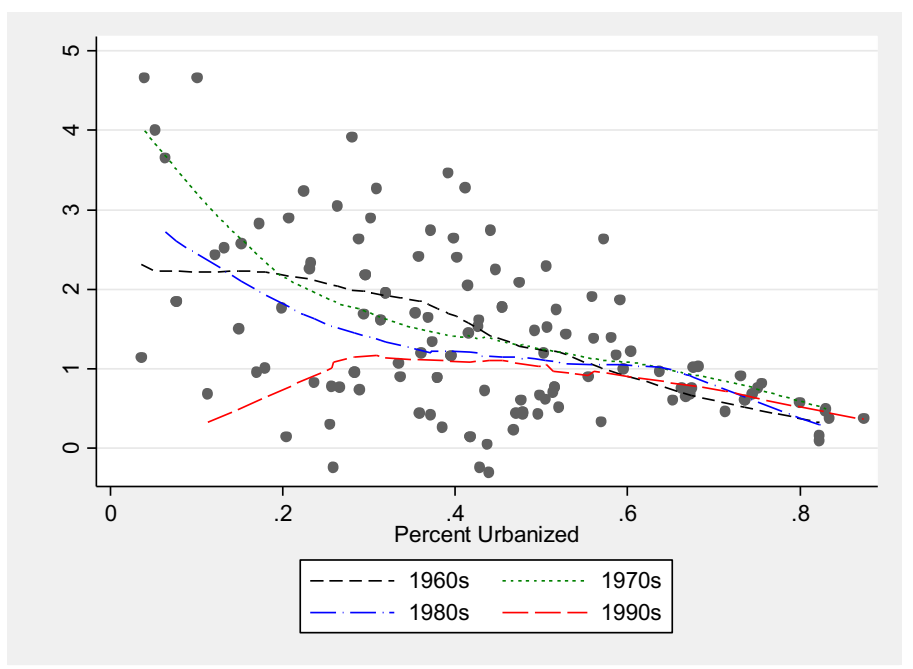

\section{Components of Urban Population Growth}

The focus of the analysis in this section, and the principle goal of this report, is on understanding what proportion of urban growth results from natural increase in the urban sector and what proportion is due to rural to urban migration and reclassification. The combination of both factors accounts for the entire change in urban population growth over a given interval leading us to show only the percentage due to natural increase in the results. The percentage due to migration or reclassification is simply the complement (100 minus the percentage due to natural increase). We consider our findings continent by continent and focus on regional-level differences, but a detailed table with all results for each country is included in Table A1 in the Appendix. Also, net rural out-migration rates and net urban in-migration rates by age and sex are presented for each country in tables $\mathrm{A} 2$ and $\mathrm{A} 3$ in the Appendix.

The CSRM generates estimates for the components of growth between any two censuses, regardless of the quality of the underlying data. As discussed earlier, the CSRM relies on a set of assumptions 
which when violated produce estimates that deviate considerably from the actual values. This deviation is an obvious source of concern. A number of countries and censuses were removed at an earlier stage due to concerns about the quality of specific census rounds. A limited number of countries were removed based on inconsistent findings for urban growth components. Deciding however which estimates should be removed from the overall analysis involves both subjective and objective criteria. Our goal was to maintain as many estimates as possible, but we removed estimates which deviated to such a great extent from surrounding years or surrounding countries as to belie any plausible explanation. In one case, Rwanda, we removed the estimate because of the unique situation faced by Rwanda following the Tutsi-Hutu civil war because of the massive civilian turmoil that ensued and the likelihood that data from this period does not reflect patterns of population mobility. Although it is nonetheless interesting to note that even in this difficult dynamic context the CSRM appears to have been successful at tracking the broad character of the shift.

When so many calculations are included across a range of countries over five separate decades and where some countries are present for most periods while others only provide estimates for one or two periods, claims about temporal patterns must be carefully weighed. Since our interest is in understanding general patterns and their evolution over time, with an understanding that these CSRM estimates can only be seen as a first order approximation, we consider our findings from a variety of perspectives and including various criteria for including or excluding countries and censuses. Also, in order to examine our estimates, and as a general strategy in this report, we focus on robust statistics - that is descriptive analysis which focus on measures that are relatively insensitive to the underlying distributional properties of the data - in additional to more traditional measures such as the average and standard deviation. We rely on box plots which provide a useful representation of a distribution across different groups or over time. The box plot is notably robust to outliers - a real factor in our results because we rely on data from a large number of statistical agencies for countries with very different demographic and socioeconomic circumstances. The robustness allows us a greater degree of assurance that the results for any single country do not overly influence our broader interpretations. Also, the box plot enables us to easily examine shifts over small or large segments of the distribution rather than solely the about the central tendency - this makes it more meaningful to both discuss broad central trends as well as differences in the degree of variability. There are four basic facts that emerge from each one of the boxes and its associated whiskers and outlier points. The most obvious feature in the box plot is the rectangular box. This box marks the inter-quartile range for the percentage role of natural increase in urban growth and this means the value for the lower 25 th percentile to the upper 75 th percentile. A shorter rectangle implies a more narrow distribution between the first and third quartile whereas lengthening the rectangles suggests a greater degree of variation in the natural increase component of urban growth. A white line dissects each of the boxes to delineate the median or 50th percentile. A line extends outwards through the box and reaching towards a bottom and top limit, which reflects the upper and lower adjacent values (Tukey 1977). The upper and lower adjacent values represent a distance above and below the upper and lower quartiles that is 1.5 times the inter-quartile range. Values beyond the adjacent values are marked as individual outliers on the figures.

\section{5a. Overall Patterns in the Components of Urban Growth over Time}


Figure 4 shows a box plot and the fundamental pattern that emerges from this analysis is clearly evident, regardless of minor variations in the methodology and the criteria that are used for inclusion or exclusion of individual countries and censuses. There is little doubt that natural increase remains the driving force behind urban growth for most countries in the developing world that are incorporated in our analysis. The median percent of urban growth that is due to natural increase consistently hovers around the 60 percent line. This was shown to be true for the period from the 1960s through the 1980 in earlier work by the United Nations (United Nations 1980, 2001). In this updated study, we show that this basic finding is unchanged when a larger group of nations are included and when the period is now extended from the 1950s through the 1990s. This basic finding is the most central result from this report and highlights the consistency of the main findings of this report with those of the earlier rounds of evaluation.

The dominant role of natural increase in urban growth, which has been shown in earlier reports on the components of urban growth (United Nations 1980, 2001), is further corroborated by the positioning of the boxes in the box plot relative to the 50 percent line. In fact, except for the 1970 s, the entire interquartile range of each of the periods lies on or above the 50 percent line. Over time, there is some shift in the outlier cases, and the magnitude of the range from the top to the bottom whisker varies as well. But there is little doubt from Figure 4 that the median as well as the more broadly defined center captured by the entire inter-quartile range - component of the distribution emphasize the dominant role of natural increase driving urban growth patterns in LDCs throughout the 40-50 year period covered in this report.

\section{Figure 4: Percentage Growth due to Natural Increase (All countries included).}

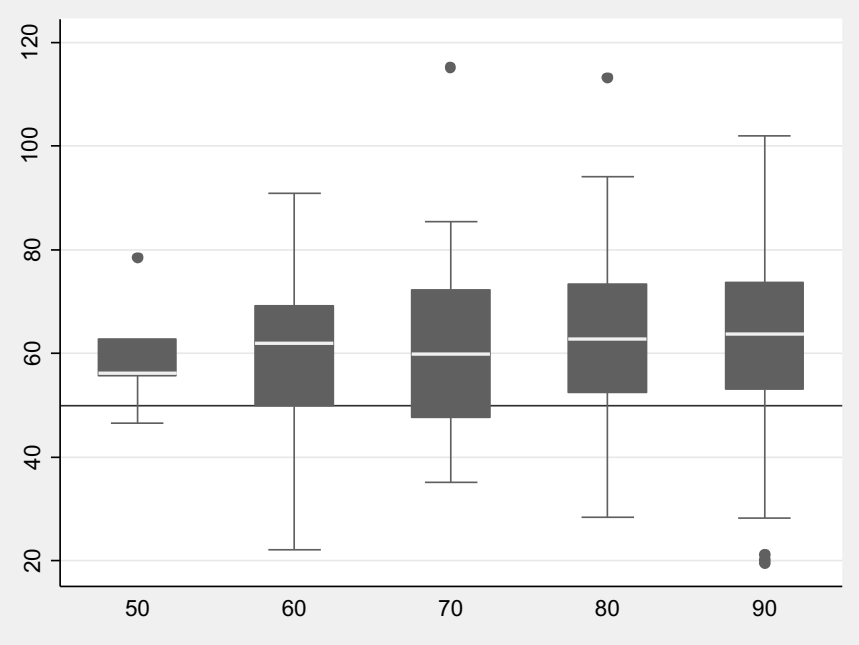

The first box plot in Figure 4 is useful for providing a general perspective on the scale of the role of natural increase relative to rural to urban migration. However, we need to be cautious when comparing the shift over time because of the period-by-period heterogeneity in the countries composing the sample that make up the box plot. In Figure 5, a similar box plot is shown but now those countries which appear in less than three intervals are excluded. This reduces the sample size considerably - both fewer countries and fewer censuses per country - but also ensures that the inter-temporal patterns are driven primarily by changes in the actual roles of natural increase and internal migration rather than 
heterogeneity in the composition of countries from decade to decade. However, notwithstanding the revised sample, the results are extremely similar. The percent of growth due to natural increase remains around 60 percent and even the bottom $25^{\text {th }}$ percentile exceeds 50 percent in all intervals but the 1970s. However, in this case, there are stronger indications of an increase in the percentage of growth due to natural increase over time. While this is not readily apparent from the median values which show no trend over time, the data provide a reasonably strong impression of an upwards shift in the inter-quartile range when comparing the period of the 1960s and 1970s to the 1980s and 1990s. Furthermore, the degree of heterogeneity in the role of natural increase appears to decline over time. The widest spread between adjacent values falls in the 1960s and is smallest in the 1990s. In addition, the inter-quartile ranges are considerably more narrow in the last two decades compared to the 1960s and 1970s. Thus, there are indications that alongside the steady role of natural increase - about 60 percent for the median value - there is a potential tendency towards convergence in patterns across countries over time possibly in line with other forms of demographic convergence (Wilson 2001).

\section{Figure 5: Percentage Growth due to Natural Increase by Interval for Countries Present at least Three Intervals}

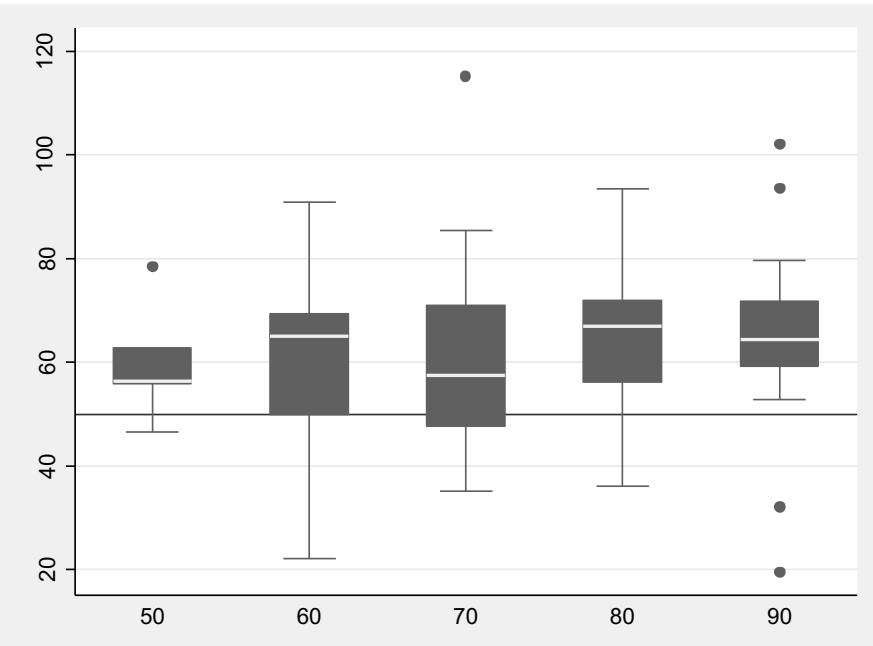

\section{5b. Components of urban growth within each continent}

Our next set of results focus on the variability in the percent of urban growth due to natural increase both over time and across continents and focuses on mean percentage values. Across all continents there is substantial variability in the actual percentage of urban growth due to natural increase and the percentage due to rural to urban migration. Overall, Table 4 shows that the average for all the continents combined hovers just under 62 percent for all decades combined. There is no obvious trend with the levels ranging around 60 percent for most periods and reaching a maximum of $64 \%$ in the $1980 \mathrm{~s}$. The average level across all periods for each continent, we also note that the results are also quite consistent. The average level in Africa and Latin American and Caribbean are nearly identical at 63 and 64 percent, respectively. The level in Asia is the lowest overall, but still lies just above 59 percent. Thus, as observed earlier with the graphical analysis, the basic story remains consistent - the majority of growth (about 62 percent) is due to natural increase. There is some variation across time and across regions but the consistency overshadows the limited degree of variation. 
Table 4: Percentage of Urban Growth due to Natural Increase for each Region and Totals. (All Countries included)

\begin{tabular}{ccccccc} 
& \multicolumn{9}{c}{ Year } \\
Continent & $\mathbf{1 9 5 0}$ 's & $\mathbf{1 9 6 0 ' s}$ & $\mathbf{1 9 7 0}$ 's & $\mathbf{1 9 8 0}$ 's & 1990's & Total \\
\hline Africa & 56.35 & 55.30 & 65.20 & 63.65 & 64.72 & 62.95 \\
Asia & & 58.43 & 59.01 & 63.34 & 51.16 & 59.13 \\
LAC & 59.89 & 62.40 & 61.26 & 66.75 & 68.72 & 63.64 \\
\hline Total & 59.30 & 59.93 & 61.68 & 64.32 & 60.81 & 61.94
\end{tabular}

The above statistics are based on all countries in the analysis. As with the earlier box plots, it makes more sense to limit the analysis to countries that are present in many if not all intervals to reduce the effect of country composition on the temporal patterns. Thus, Table 5 repeats the analysis but including only countries present for at least three census intervals. This reduces the number of countries in the analysis from 76 that are included in Table 4 to 39 that are included in Table 5. This shift in approach highlights the stability of our basic results as well as the heterogeneity that appears to exist across continents. First, note that the grand mean remains essentially unchanged at just under 62 percent in Table 5. However, the decadal averages across countries now show a clearer increase in the role of natural increase from the period from the 70 and earlier of around 58-60 percent to the period of the $80 \mathrm{~s}$ and 90 s of around 65 percent. This increase in the role of natural increase is now more compelling because it is not driven by the changing composition of countries in the table by period. Furthermore, we also note that inter-continental differences are now also considerably wider, with Africa's percent of urban growth due to natural increase at 67 percent, Latin American and Caribbean's at 64 percent, and Asia lower at 57 percent. Nonetheless, despite this gap between Asia and the two other regions, growth in Asian urban populations is still predominately due to natural increase and ranges between 54-60 percent over the four intervals with no obvious temporal pattern. On the other hand, the patterns in both Latin American and Caribbean and in Africa both show a slight if non-monotonic tendency towards an increasing role for natural increase in urban growth over time. In Africa, the period of the 90 s shows a level of 76 percent - the highest seen in Table 5 - and almost 20 percentage points greater than the level prior to the 70s. In Latin American and Caribbean, the level prior to the 80s stood between 60-63 percent but reached between 68-69 percent in the $80 \mathrm{~s}$ and $90 \mathrm{~s}$. The overall trend towards an increase for all regions combined appears to be driven due to the trends seen in Africa and Latin America and Caribbean with a moderating effect due to the Asian trend. As we will see later, the trend is Asia is very influenced by the case of China, which stands out as an outlier in these findings.

One should recall that there are several cases in both of the above tables where country estimates appear in duplicate because the intervals between the censuses are particularly long. We have 14 such duplicates in our data. The nature of the duplicates is to reduce the variability over time but it also creates an illusion that certain countries appear in more intervals because of this approach to coding the data. We have replicated the same analysis as in Table 5 but without the duplicates and the results are very similar. The temporal trends are little changed, although there is a slight decline in the role of natural increase for Africa from the 70s and onwards and for Asia. The values for LAC are unchanged. The overall average role of natural increase declines from 62 percent to 60 . Otherwise, however, the basic impressions described above are unchanged. 
Table 5: Percentage of Urban Growth due to Natural Increase for each Region and Totals. (Includes only Countries with at least Three Intervals)

\begin{tabular}{crrrrrr} 
& \multicolumn{6}{c}{ Year } \\
Continent & $\mathbf{1 9 5 0 ' s}$ & $\mathbf{1 9 6 0 ' s}$ & $\mathbf{1 9 7 0}$ 's & $\mathbf{1 9 8 0}$ 's & $\mathbf{1 9 9 0 ' s}$ & Total \\
\hline Africa & 56.35 & 56.20 & 71.62 & 65.27 & 75.86 & 66.72 \\
Asia & & 59.33 & 55.62 & 60.01 & 53.70 & 57.37 \\
LAC & 60.94 & 63.00 & 60.82 & 67.77 & 68.72 & 64.10 \\
\hline Total & 60.02 & 60.76 & 61.31 & 64.32 & 64.70 & 62.46
\end{tabular}

It is also useful to consider the degree of variation within each of the regions across time. In Figure 6 below we show a box plot diagram for each of the regions when all intervals are combined. The figure clearly demonstrates the presence of outliers in Africa - where we note two cases where the natural increase component accounts for over 110 percent of urban growth. On the other hand, the interquartile range for Asia is even wider than what we find for Africa. Thus, a case can be made for either region displaying the greater level variability in the role of natural increase. At the same time, the smallest degree of variability in the role of natural increase is in LAC, where both the inter-quartile range and the spread between the adjacent values is considerably smaller than what we see in the other two regions.

Figure 6: Box Plot of Regional Variation in the Role of Natural Increase for all Periods (All Countries)

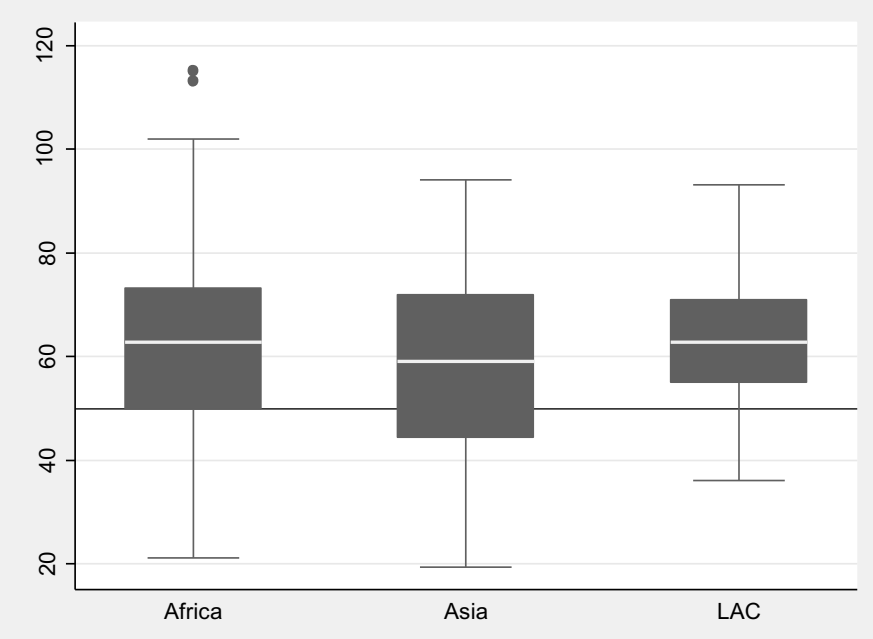

Despite the impressive consistency in these findings in aggregate, the continental differences point to some notable geographic variation and this variation is further evident once we begin to look within continents. The country-level results for Africa are shown below in Table 6 . The table first shows the relative paucity of census data for many countries in Africa. This means that there are few countries where we can clearly identify trends over time and there are many more countries, such as Benin, Cape Verde, Namibia, Senegal, and Swaziland, with only one observation provided for our analysis (including 
duplicate entries). On the other hand, there are only 8 countries with 3 or more observations and only 4, including Egypt, Ghana, Morocco, and South Africa, which provide four observations.

If we consider some of the countries in more detail, we note the high degree of heterogeneity from round to round in the results - even after several of the more abrupt inter-decadal shifts have been cleaned from the data. Yet, there is also some encouraging signs that the CSRM method is powerful enough to capture some anticipated demographic shifts. Rwanda is a case in point. Whereas natural increase contributed 63 percent of urban growth during the 80s, near the overall average, its contribution plummeted to 21 percent during the $90 \mathrm{~s}$. This decline is certainly in line with expectations for the tumultuous period during and following the 1994 genocide in Rwanda, which led to migration both outside of Rwanda as well as considerable population redistribution within the state's borders. On the other hand, the increase in the role of natural increase in Egypt's urban growth to 93 and then 102 percent might be driven by changes in census quality over time rather than a lack of rural to urban migration.

Table 6: Percent of urban growth due to Natural Increase for countries in Africa, 1950s-1990s

\begin{tabular}{|c|c|c|c|c|c|c|}
\hline & \multirow[b]{2}{*}{ Country } & \multicolumn{5}{|c|}{ Year } \\
\hline & & 1950 's & 1960's & $\overline{1970 ' s}$ & 1980's & 1990's \\
\hline \multirow[t]{9}{*}{ Eastern Africa } & Ethiopia & & & & 49.1 & \\
\hline & Kenya & & & 40.6 & 62.9 & \\
\hline & Madagascar & & & & 57.6 & \\
\hline & Mauritius & & & 115.1 & 93.4 & 93.4 \\
\hline & Rwanda & & & & 62.8 & 21.2 \\
\hline & Uganda & & & 67.0 & 67.0 & 71.7 \\
\hline & Tanzania & & & 37.9 & 47.4 & \\
\hline & Zambia & & & 73.0 & 113.1 & \\
\hline & Zimbabwe & & & 37.8 & 47.5 & \\
\hline \multirow[t]{5}{*}{ Northern Africa } & Egypt & & 69.2 & 69.2 & 92.9 & 101.9 \\
\hline & Libya & & 43.2 & 70.7 & & \\
\hline & Morocco & & 64.6 & 55.8 & 50.8 & 59.4 \\
\hline & Sudan & & & 80.1 & & \\
\hline & Tunisia & & 48.2 & 72.2 & 59.8 & \\
\hline \multirow[t]{4}{*}{ Southern Africa } & Botswana & & 22.1 & 47.1 & 36.1 & \\
\hline & Namibia & & & & & 41.3 \\
\hline & South Africa & 56.4 & 74.1 & 69.3 & 69.3 & \\
\hline & Swaziland & & & & & 65.5 \\
\hline \multirow[t]{10}{*}{ Western Africa } & Benin & & & & & 73.7 \\
\hline & Burkina Faso & & & & 42.4 & \\
\hline & Cape Verde & & & & & 53.0 \\
\hline & Cote d'Ivoire & & & & 76.6 & \\
\hline & Ghana & & 59.0 & 77.3 & 52.9 & 52.9 \\
\hline & Liberia & & & 65.0 & & \\
\hline & Mali & & & & 50.3 & \\
\hline & Niger & & & & 73.3 & 77.9 \\
\hline & Senegal & & & & 74.4 & \\
\hline & Togo & & 62.0 & & & \\
\hline Central Africa & Cameroon & & & & 57.1 & \\
\hline
\end{tabular}

The data on Asia are shown in a single table below (Table 7). In this case there are no estimates for the 1950s period. However, following the 1950s, there is more consistency in Asia than in Africa in the number of estimates per country. There are several cases, however, where the numbers highlight dramatic shifts in the role of natural increase. For example, for Armenia we see a 50 percentage point 
decline in the role of natural increase from the 80 s to the 90 s. On the other hand, there are also some interesting trends that may be meaningful indicators of a shift across parts of Asia. In Indonesia, the percentage due to natural increase gradually declines from 70 percent to 32 percent over the course of four decades. In Nepal, this decline is from 68 percent in the 60 s to 36 percent in the 80 s and we note a dramatic shift in Thailand where the role of natural increase decreases from 56 percent in the 80 s to 19 percent in the 90s. Whether these declines are due in fact to a relative increase in the role of migration from rural to urban sectors or whether they are capturing more aggressive state policies of urban reclassification is not possible to determine using this method. Nonetheless, the shift is quite marked and stands somewhat apart from most other regions of the developing world.

This report is also the first to estimate the components of urban growth for the states that were in the former Soviet Union. With some exceptions, including Georgia and Kazakhstan in the 80s and Armenia in the 90s, the estimates of the natural increase component of urban growth are very high. For example, the estimates for Armenia and Uzbekistan for the 80s are 78 and 80 percent, respectively. In Tajikistan in the $80 \mathrm{~s}$, natural increase is estimated to account for 93 percent of urban growth and it is estimated to account for 75 percent of urban growth in Kyrgyzstan over the same period. Assuming that these numbers are accurate, they may well reflect a situation where mobility was regulated before the breakup of the Soviet Union. One might expect to see a greater expansion than we can currently identify in the role of rural to urban migration over the $90 \mathrm{~s}$ - except for the case of Armenia where we note a dramatic and perhaps suspect decline in the role of natural increase -but this pattern is likely to change over time.

The results for India and China are definitely worth singling out due to the sheer sizes of their populations but also because of their particular patterns. In China, natural increase accounts for only 28 percent of urban growth in the $80 \mathrm{~s}$ and 20 percent in the $90 \mathrm{~s}$. This percentage lies in the bottom of the distribution and at least two standard deviation ( $\mathrm{sd}=17$ percentage points) below the overall mean (62 percent). In India, where estimates can be generated for each of the decades since the $60 \mathrm{~s}$, there is considerable variation across decades but no clear trend and the overall average is right at 65 percent just slightly above the mean across all countries and time periods.

Table 7: Percent of Urban Growth due to Natural Increase for Countries in Asia, 1950s-1990s.

\begin{tabular}{|c|c|c|c|c|c|c|}
\hline & Country & 1950's & 1960 's & $\frac{\text { Year }}{1970 \text { 's }}$ & 1980 's & 1990's \\
\hline \multirow[t]{2}{*}{ Eastern Asia } & China & & & & 28.4 & 20.0 \\
\hline & Republic of Korea & & 38.8 & 42.9 & 44.6 & 61.7 \\
\hline \multirow[t]{5}{*}{ South-Eastern Asia } & Indonesia & & 70.2 & 49.9 & 41.2 & 32.1 \\
\hline & Malaysia & & & 44.5 & 60.1 & 59.2 \\
\hline & Myanmar & & & 81.9 & & \\
\hline & Philippines & & & 59.1 & 47.1 & \\
\hline & Thailand & & & 42.0 & 56.2 & 19.4 \\
\hline \multirow[t]{7}{*}{ Western Asia } & Armenia & & & & 78.0 & 28.2 \\
\hline & Georgia & & & & 53.9 & \\
\hline & Iraq & & 53.8 & 68.1 & 75.1 & \\
\hline & Israel & & & 82.0 & 94.0 & \\
\hline & Jordan & & 85.4 & 85.4 & 72.6 & \\
\hline & Syria & & 68.7 & 78.9 & 84.0 & \\
\hline & Turkey & & 38.3 & 46.9 & 56.2 & 56.2 \\
\hline \multirow[t]{2}{*}{ South-Central Asia } & Bangladesh & & 42.0 & 35.1 & 43.6 & \\
\hline & India & & 69.1 & 55.3 & 71.9 & 63.2 \\
\hline
\end{tabular}




$\begin{array}{lllll}\text { Iran } & & 57.2 & 70.4 & \\ \text { Kazakhstan } & & & 55.9 & 85.0 \\ \text { Kyrgyzstan } & & & 75.2 & \\ \text { Maldives } & & 47.7 & 68.7 & 68.1 \\ \text { Nepal } & 67.6 & 41.1 & 36.3 & \\ \text { Pakistan } & & 85.2 & 69.7 & 69.7 \\ \text { Sri Lanka } & 50.4 & & & \\ \text { Tajikistan } & & & 93.4 & \\ \text { Uzbekistan } & & & 80.4 & \end{array}$

As noted earlier, the countries in Latin America and the Caribbean provide the most complete census coverage and there is considerably less variation in the estimates generated both across countries and over time when all data are used. From our entire list of Latin American and Caribbean countries, Bolivia and Nicaragua are the only states that provide only a single observation for our analysis and most countries provide three or four observations. Also, this is the only one of the three regions we examined where we have estimates for multiple countries for the 1950s. These estimates for the 50s range from 47 percent in Haiti to 78 percent in Cuba. Interestingly, for LAC, there are few cases overall where the percentage of urban growth due to natural increase falls below 50 percent, and this in fact does not occur for any of the ten countries in the South American region of LAC.

The results in Table 8 also suggest a trend towards a greater role for natural increase in urban growth over time in the region. In particular, from the $80 \mathrm{~s}$ and $90 \mathrm{~s}$, we note that there are no cases in any of the countries where natural increase comprises less than 50 percent of urban growth. If we examine the 17 countries providing at least one data point for either the $80 \mathrm{~s}$ or $90 \mathrm{~s}$, only four of those countries provide estimates that are between 50-60 percent, while the remaining countries provide estimates that are above 60 percent. This apparent increase in the role of natural increase, at least of the countries in Latin America and the Caribbean in our analysis, provides a strong indication of the continued strength of demographic forces at work in urban growth in the region.

Table 8: Percent of Urban Growth due to Natural Increase for Countries in Latin America and the Caribbean, 1950s-1990s.

\begin{tabular}{|c|c|c|c|c|c|c|}
\hline & Country & 1950 's & 1960 's & $\frac{\text { Year }}{1970 \text { 's }}$ & 1980 's & 1990 's \\
\hline \multirow[t]{12}{*}{ Central America and Caribbean } & Costa Rica & & 57.5 & 68.7 & & \\
\hline & Cuba & 78.4 & 78.4 & 43.5 & & \\
\hline & Dominican Republic & 55.9 & 51.6 & 55.1 & & 57.1 \\
\hline & El Salvador & & 78.4 & 52.5 & 52.5 & \\
\hline & Guatemala & 55.7 & 62.2 & & & \\
\hline & Haiti & 46.6 & 46.6 & 84.1 & & \\
\hline & Honduras & & 49.8 & 60.7 & 60.7 & \\
\hline & Jamaica & & 41.9 & 41.9 & 69.1 & 78.8 \\
\hline & Mexico & & 68.1 & 71.0 & 68.7 & 76.3 \\
\hline & Nicaragua & & 56.9 & & & \\
\hline & Panama & & 58.9 & 68.5 & 70.6 & \\
\hline & Puerto Rico & & 36.1 & 55.0 & 61.4 & \\
\hline \multirow[t]{5}{*}{ South America } & Argentina & & 69.3 & 69.3 & 73.1 & \\
\hline & Bolivia & & & & 52.5 & \\
\hline & Brazil & & 51.6 & 52.4 & 62.0 & 64.3 \\
\hline & Chile & & 65.1 & 73.4 & 93.1 & 79.6 \\
\hline & Colombia & 62.8 & 76.1 & & 71.8 & \\
\hline
\end{tabular}




$\begin{array}{ccccc}\text { Ecuador } & 67.7 & 52.2 & 57.4 & 65.3 \\ \text { Paraguay } & 66.6 & 52.5 & 58.5 & 60.2 \\ \text { Peru } & 58.0 & 67.4 & 70.6 & \\ \text { Uruguay } & 90.8 & 59.1 & & 68.2 \\ \text { Venezuela } & 78.8 & 75.4 & 79.6 & \end{array}$

\section{5c. A Population-Weighted Approach to Estimating the Components of Urban Growth}

So far our emphasis has been on examining the components of urban growth as the state level paying equal weight to large and small states. This is a sensible approach because internal migration is by definition a state-level process. Examining the shift in the population balance for countries from the rural to the urban sector is appropriately measured at the country level, and for this reason it also makes sense to calculate the broader-level aggregates as the average process across countries. Nonetheless, it is also interesting to explore the components of urban growth from an alternative perspective (Chen et al. 1998). This involves looking at urbanization and its components by summing people across countries, paying no attention to the political units in which they reside. Essentially, this means recalculating the estimated levels for continents and for the world as a whole using population sizes as the weights for each country.

The results in Table 9 show the implications of calculating the aggregate estimates when population weights are used for each of the countries. The obvious result of this revised procedure is that countries with relatively large populations exert particularly large influences on the findings. This means that China and India in particular, and several other large countries to a lesser extent, are going to exert a very large influence on the overall estimate of the components of growth when the estimates are weighted by population size. Given our earlier finding regarding China, a large outlier, we fully expect to find a shift in the overall pattern once the weight of China's population is included. Another indirect implication is that because countries are not consistently in the data, the population weighted estimates will be particularly sensitive to the appearance and disappearance of large countries from the overall aggregate estimate. This issue reduces the utility of using the population weighted estimates for examining time trends.

If we examine the world as a whole, there is a notable change in the basic result we identified in the other sections of this report. The proportion of urban growth that is due to natural increase consistently declines from 58 percent in the 1960 s to 41 percent in the 1990s. In this case, the effect of China, where the fraction of urban growth due to natural increase is about 20 percent and which enters our data only from the 1980s, exerts a tremendous influence and pulls down the overall mean. This is readily apparent from the bottom row in the table which shows the overall mean estimate when China is not included in the sample. Thus, China's tremendous population size is a great influence on the overall trend and leads to a very different perspective.

When the results are examined region by region, the contrasting patterns are equally apparent. Asia's urban growth is generated mostly by natural increase in the $1960 \mathrm{~s}$ (59 percent) but this percentage declines to just over one-third (35 percent) by the 1990s. On the other hand, the pattern in Africa is consistent with our earlier findings and hovers around 60 percent for most of the decades. In Latin America and the Caribbean, the findings suggest an increasing role of natural increase over time 
with 60 percent of urban growth driven by natural increase in the 1960s and 66 or more percent from the 1980s and onwards.

Thus, shifting the method of analysis from one based on states to one that is based on the aggregation of populations creates some interesting variation in the main findings. Urban growth in both Latin American and the Caribbean and in Africa continue to be primarily driven by natural increase nearly two-thirds - as we noted in the earlier section. However, the estimated components of urban growth in Asia and the world as a whole is seriously affected by the results for China. Ultimately, policies are enacted by states and thus states are the natural unit for this analysis. When populations are used without accounting for states, we end up finding that the proportion of world urbanization that is due to natural increase declines and falls below half. However, it turns out that this is solely due to the inclusion of China. When China is excluded, it turns out that our initial assessment when the countrylevel averages were used is unchanged and natural increase continues to dominate as the principle component of urban growth.

Table 9: Percent of Urban Growth due to Natural Increase for each Continent and Total for the World with and without China, 1960s-1990s, Weighted by Population Size.

\begin{tabular}{ccccc} 
Continent & $\mathbf{1 9 6 0}$ 's & $\mathbf{1 9 7 0}$ 's & $\mathbf{1 9 8 0}$ 's & 1990's \\
\hline Africa & 63.26 & 60.32 & 58.33 & 65.40 \\
Asia & 59.32 & 53.99 & 46.18 & 34.78 \\
LAC & 60.35 & 60.12 & 66.46 & 67.91 \\
\hline Total & 58.17 & 55.64 & 51.41 & 40.59 \\
Total Excluding China & 58.17 & 55.64 & 61.11 & 57.44
\end{tabular}




\section{Conclusion}

The growth in the urban population is also part of a broader trend of growing world population sizes. This impressive growth of the world population has been slowing in recent decades as most countries around the world have initiated fertility declines and as many countries in the West have seen fertility rates fall well below replacement levels. However, just as population momentum continues to drive forward world population growth as countries with young age structures maintain high levels of birth rates, urban population growth continues propelled forward by both high rates of natural increase within the urban sector as well as continued rural to urban migration patterns. Both of these mechanisms play a vital role in urban population growth, as is obvious by the increasing share of the world population residing in cities.

The United Nations has contributed two prior reports that are widely used to gauge the components of urban growth in the developing world (United Nations 1980, 2001). This current report presents a new and revised set of estimates of the components of urban growth. The dominant lesson from this report is that prior results which clearly showed natural increase to be the driving force overall in the world for urban growth continues to be the principle mechanism. For the developing world as a whole, we find that 62 percent of urban growth is due to natural increase while only 38 percent is due to net rural to urban migration. The analysis further shows that while natural increase is clearly responsible for the majority of the growth in urban areas, this does vary considerably both over time and across countries and regions. In regions where we have the most consistent data, LAC, there are signs that the role of natural increase is not diminishing and even increasing over time. A similar perspective is shown

for data from Africa - if not as strong. In contrast, in Asia, there are signs that the role of natural increase is declining. 


\section{References}

Chattopadhyay, A., M.J. White, and C. Debpuur. 2006. "Migrant fertility in Ghana: Selection versus adaptation and disruption as causal mechanisms." Population Studies-a Journal of Demography 60(2):189-203.

Chen, N.Y.-P., P. Valente, and H. Zlotnik. 1998. "What do we know about recent trends in urbanization." Pp. 59-88 in Migration, Urbanization, and Development: New Directions and Crises, edited by R. Bilsborrow. New York: United Nations Fund for Population Activities.

Cohen, B. 2004. "Urban growth in developing countries: A review of current trends and a caution regarding existing forecasts." World Development 32(1):23-51.

Goldstein, S. 1990. "Urbanization in China, 1982-87 - Effects of Migration and Reclassification." Population and Development Review 16(4):673-701.

Jensen, E.R.and D.A. Ahlburg. 2004. "Why does migration decrease fertility? Evidence from the Philippines." Population Studies-a Journal of Demography 58(2):219-231.

Montgomery, M., R. Stren, B. Cohen, and H.E. Reed. 2003. Cities transformed : demographic change and its implications in the developing world. Washington, DC: National Academies Press.

Pejaranonda, C., S. Santipaporn, and P. Guest. 1995. "Rural-Urban migration in Thailand." Pp. 171-243 in Trends, Patterns and Implications of Rural-Urban Migration in India, Nepal and Thailand. New York: United Nations.

Pernia, E. 1976. "A Method of Decomposing Urban Population Growth and an Application to Philippine Data." Honolulu: East-West Center Population Institute.

Preston, S.H. 1979. "Urban-Growth in Developing-Countries - Demographic Reappraisal." Population and Development Review 5(2):195-215.

Rogers, A. 1982. "Sources of Urban-Population Growth and Urbanization, 1950-2000 - a Demographic Accounting." Economic Development and Cultural Change 30(3):483-506.

United Nations. 1980. "Patterns of Urban and Rural Population Growth." United Nations.

—. 2001. "The Components of Urban Growth in Developing Countries." New York.

—. 2007. "World Urbanization Prospects." New York: United Nations.

White, M.J., L. Moreno, and S.Y. Guo. 1995. "The Interrelation of Fertility and Geographic-Mobility in Peru - a Hazards Model Analysis." International Migration Review 29(2):492-514.

White, M.J., E. Tagoe, C. Stiff, K. Adazu, and D.J. Smith. 2005. "Urbanization and the fertility transition in Ghana." Population Research and Policy Review 24(1):59-83.

Wilson, C. 2001. "On the Scale of Global Demographic Convergence: 1950-2000." Population and Development Review 27(1):155-171. 


\section{Appendices}

Table A1.

\begin{tabular}{|c|c|c|c|c|c|c|c|}
\hline & & \multirow{2}{*}{ Country } & \multicolumn{5}{|c|}{ Year } \\
\hline & & & 1950's & 1960's & $\overline{1970 ' s}$ & 1980's & 1990's \\
\hline \multirow[t]{29}{*}{ Africa } & \multirow[t]{9}{*}{ Eastern Africa } & Ethiopia & & & & 49.14 & \\
\hline & & Kenya & & & 40.62 & 62.89 & \\
\hline & & Madagascar & & & & 57.61 & \\
\hline & & Mauritius & & & 115.09 & 93.39 & 93.39 \\
\hline & & Rwanda & & & & 62.81 & 21.23 \\
\hline & & Uganda & & & 66.95 & 66.95 & 71.73 \\
\hline & & Tanzania & & & 37.94 & 47.40 & \\
\hline & & Zambia & & & 72.95 & 113.06 & \\
\hline & & Zimbabwe & & & 37.76 & 47.52 & \\
\hline & \multirow[t]{5}{*}{ Northern Africa } & Egypt & & 69.18 & 69.18 & 92.93 & 101.92 \\
\hline & & Libya & & 43.19 & 70.69 & & \\
\hline & & Morocco & & 64.59 & 55.76 & 50.82 & 59.42 \\
\hline & & Sudan & & & 80.08 & & \\
\hline & & Tunisia & & 48.24 & 72.22 & 59.81 & \\
\hline & \multirow[t]{4}{*}{ Southern Africa } & Botswana & & 22.12 & 47.07 & 36.10 & \\
\hline & & Namibia & & & & & 41.28 \\
\hline & & South Africa & 56.35 & 74.07 & 69.32 & 69.32 & \\
\hline & & Swaziland & & & & & 65.53 \\
\hline & \multirow{10}{*}{ Western Africa } & Benin & & & & & 73.70 \\
\hline & & Burkina Faso & & & & 42.40 & \\
\hline & & Cape Verde & & & & & 52.99 \\
\hline & & Cote d Ivoire & & & & 76.64 & \\
\hline & & Ghana & & 59.03 & 77.34 & 52.86 & 52.86 \\
\hline & & Liberia & & & 65.03 & & \\
\hline & & Mali & & & & 50.27 & \\
\hline & & Niger & & & & 73.27 & 77.90 \\
\hline & & Senegal & & & & 74.36 & \\
\hline & & Togo & & 61.97 & & & \\
\hline & Central Africa & Cameroon & & & & 57.11 & \\
\hline \multirow[t]{25}{*}{ Asia } & \multirow{2}{*}{ Eastern Asia } & China & & & & 28.40 & 20.00 \\
\hline & & Republic of Korea & & 38.80 & 42.93 & 44.62 & 61.72 \\
\hline & \multirow[t]{5}{*}{ South-Eastern Asia } & Indonesia & & 70.21 & 49.87 & 41.19 & 32.09 \\
\hline & & Malaysia & & & 44.52 & 60.09 & 59.19 \\
\hline & & Myanmar & & & 81.86 & & \\
\hline & & Philippines & & & 59.14 & 47.09 & \\
\hline & & Thailand & & & 41.99 & 56.21 & 19.39 \\
\hline & \multirow[t]{7}{*}{ Western Asia } & Armenia & & & & 78.02 & 28.17 \\
\hline & & Georgia & & & & 53.86 & \\
\hline & & Iraq & & 53.81 & 68.12 & 75.12 & \\
\hline & & Israel & & & 82.03 & 94.03 & \\
\hline & & Jordan & & 85.42 & 85.42 & 72.58 & \\
\hline & & Syria & & 68.71 & 78.89 & 84.00 & \\
\hline & & Turkey & & 38.32 & 46.94 & 56.22 & 56.22 \\
\hline & \multirow{11}{*}{ South-Central Asia } & Bangladesh & & 42.01 & 35.11 & 43.59 & \\
\hline & & India & & 69.10 & 55.31 & 71.91 & 63.20 \\
\hline & & Iran & & & 57.19 & 70.38 & \\
\hline & & Kazakhstan & & & & 55.93 & 85.01 \\
\hline & & Kyrgyzstan & & & & 75.16 & \\
\hline & & Maldives & & & 47.66 & 68.70 & 68.08 \\
\hline & & Nepal & & 67.60 & 41.08 & 36.28 & \\
\hline & & Pakistan & & & 85.16 & 69.68 & 69.68 \\
\hline & & Sri Lanka & & 50.36 & & & \\
\hline & & Tajikistan & & & & 93.43 & \\
\hline & & Uzbekistan & & & & 80.42 & \\
\hline \multirow[t]{3}{*}{ LAC } & \multirow[t]{3}{*}{ Central America and Caribbean } & & & & & & \\
\hline & & Costa Rica & & 57.47 & 68.67 & & \\
\hline & & Cuba & 78.42 & 78.42 & 43.53 & & \\
\hline
\end{tabular}


South America

Dominican Republic
El Salvador
Guatemala
Haiti
Honduras
Jamaica
Mexico
Nicaragua
Panama
Puerto Rico
Argentina
Bolivia
Brazil
Chile
Colombia
Ecuador
Paraguay
Peru
Uruguay
Venezuela

$\begin{array}{cc}55.89 & 51.60 \\ 55.71 & 78.44 \\ 46.59 & 62.17 \\ & 46.59 \\ & 49.77 \\ & 41.94 \\ & 68.11 \\ & 56.94 \\ & 58.93 \\ & 36.10 \\ & 69.25 \\ & 51.58 \\ & 65.13 \\ 62.84 & 76.14 \\ & 67.73 \\ & 66.58 \\ & 57.98 \\ & 90.85 \\ & 78.77\end{array}$

55.08

52.46

84.12

60.69

41.94

71.05

68.48

55.04

69.25

52.41

73.38

52.24

52.49

67.45

59.05

75.36
57.06

52.46

60.69

$69.05 \quad 78.81$

$\begin{array}{ll}68.68 & 76.33\end{array}$

70.56

61.44

73.08

52.48

61.99

93.08

71.77

57.37

58.51

70.55

79.60
64.27

79.57

65.28

60.23

68.16 
Table A2. Age-specific net out-migration rates from rural areas by sex and age groups

\begin{tabular}{|c|c|c|c|c|c|c|c|c|c|c|c|c|c|}
\hline \multirow{2}{*}{\multicolumn{2}{|c|}{ Region, subregion and country }} & \multirow{2}{*}{\multicolumn{2}{|c|}{ Intercensal interval }} & \multicolumn{5}{|c|}{$\begin{array}{c}\text { Male } \\
\text { Age groups }\end{array}$} & \multicolumn{5}{|c|}{$\begin{array}{c}\text { Female } \\
\text { Age groups }\end{array}$} \\
\hline & & & & $0-14$ & $15-29$ & $30-44$ & $45-64$ & $65+$ & $0-14$ & $15-29$ & $30-44$ & $45-64$ & $65+$ \\
\hline \multicolumn{14}{|l|}{ Africa } \\
\hline \multicolumn{14}{|l|}{ Eastern Africa } \\
\hline & Ethiopia & 1984 & 1994 & 0.003 & 0.006 & 0.002 & 0.002 & 0.001 & 0.004 & 0.002 & 0.000 & 0.004 & 0.003 \\
\hline & Kenya & 1969 & 1979 & 0.005 & 0.022 & 0.003 & -0.001 & 0.001 & 0.006 & 0.010 & 0.002 & 0.003 & 0.003 \\
\hline & Kenya & 1979 & 1989 & 0.000 & 0.020 & -0.004 & -0.008 & -0.004 & 0.001 & 0.008 & -0.004 & -0.003 & -0.003 \\
\hline & Madagascar & 1975 & 1993 & 0.005 & 0.004 & 0.006 & 0.004 & 0.002 & 0.006 & 0.004 & 0.007 & 0.005 & 0.003 \\
\hline & Mauritius & 1972 & 1983 & -0.001 & -0.002 & 0.000 & 0.000 & -0.004 & -0.001 & -0.002 & -0.001 & 0.000 & -0.003 \\
\hline & Mauritius & 1983 & 2000 & 0.004 & -0.004 & 0.004 & 0.000 & 0.000 & 0.004 & -0.002 & 0.003 & 0.000 & -0.001 \\
\hline & Rwanda & 1978 & 1991 & 0.001 & 0.003 & -0.001 & -0.001 & -0.001 & 0.001 & 0.002 & 0.000 & 0.000 & 0.000 \\
\hline & Rwanda & 1991 & 2002 & 0.010 & 0.022 & 0.015 & 0.011 & 0.007 & 0.010 & 0.013 & 0.007 & 0.008 & 0.008 \\
\hline & Uganda & 1969 & 1991 & 0.002 & 0.006 & -0.004 & -0.002 & -0.001 & 0.003 & 0.004 & -0.002 & 0.000 & 0.001 \\
\hline & Uganda & 1991 & 2002 & 0.001 & 0.007 & -0.004 & -0.002 & 0.000 & 0.002 & 0.003 & -0.003 & 0.000 & 0.001 \\
\hline & Tanzania & 1967 & 1978 & 0.008 & 0.017 & 0.008 & 0.004 & 0.003 & 0.009 & 0.011 & 0.006 & 0.005 & 0.004 \\
\hline & Tanzania & 1978 & 1988 & 0.005 & 0.011 & 0.002 & 0.002 & 0.001 & 0.006 & 0.008 & 0.002 & 0.003 & 0.003 \\
\hline & Zambia & 1974 & 1980 & 0.007 & 0.022 & 0.001 & -0.008 & 0.000 & 0.010 & 0.014 & 0.000 & 0.001 & 0.005 \\
\hline & Zambia & 1980 & 1990 & -0.002 & 0.006 & -0.006 & -0.019 & -0.006 & 0.000 & 0.001 & -0.011 & -0.008 & -0.003 \\
\hline & Zimbabwe & 1969 & 1982 & 0.006 & 0.030 & 0.000 & -0.002 & -0.004 & 0.008 & 0.017 & 0.003 & -0.002 & -0.005 \\
\hline & Zimbabwe & 1982 & 1992 & 0.007 & 0.036 & 0.008 & -0.004 & -0.008 & 0.010 & 0.025 & 0.003 & -0.003 & -0.003 \\
\hline \multicolumn{14}{|l|}{ Northern Africa } \\
\hline & Egypt & 1960 & 1976 & 0.005 & 0.014 & 0.007 & 0.004 & -0.003 & 0.007 & 0.009 & 0.004 & 0.003 & -0.001 \\
\hline & Egypt & 1976 & 1986 & 0.002 & 0.004 & 0.001 & 0.000 & -0.009 & 0.003 & 0.001 & 0.000 & 0.000 & -0.006 \\
\hline & Egypt & 1986 & 1996 & 0.001 & 0.001 & -0.001 & -0.001 & -0.011 & 0.001 & 0.000 & -0.001 & -0.001 & -0.011 \\
\hline & Libya & 1964 & 1973 & 0.063 & 0.080 & 0.078 & 0.048 & 0.034 & 0.065 & 0.069 & 0.060 & 0.047 & 0.039 \\
\hline & Libya & 1973 & 1984 & 0.044 & 0.052 & 0.030 & 0.033 & 0.029 & 0.044 & 0.053 & 0.045 & 0.047 & 0.037 \\
\hline & Morocco & 1960 & 1971 & 0.008 & 0.007 & 0.008 & -0.002 & 0.001 & 0.013 & 0.002 & 0.008 & 0.004 & 0.002 \\
\hline & Morocco & 1971 & 1982 & 0.012 & 0.026 & 0.014 & 0.005 & -0.002 & 0.014 & 0.013 & 0.011 & 0.006 & 0.001 \\
\hline & Morocco & 1982 & 1994 & 0.016 & 0.022 & 0.016 & 0.007 & 0.004 & 0.017 & 0.020 & 0.017 & 0.011 & 0.003 \\
\hline & Morocco & 1994 & 2004 & 0.011 & 0.012 & 0.007 & 0.002 & -0.003 & 0.011 & 0.015 & 0.008 & 0.005 & 0.001 \\
\hline & Sudan & 1973 & 1983 & 0.003 & 0.006 & -0.002 & 0.001 & 0.000 & 0.003 & 0.000 & 0.002 & 0.003 & 0.002 \\
\hline & Tunisia & 1966 & 1975 & 0.022 & 0.015 & 0.021 & 0.014 & 0.003 & 0.023 & 0.022 & 0.022 & 0.017 & 0.005 \\
\hline & Tunisia & 1975 & 1984 & 0.010 & 0.015 & 0.008 & 0.004 & -0.002 & 0.011 & 0.009 & 0.006 & 0.007 & 0.006 \\
\hline & Tunisia & 1984 & 1994 & 0.021 & 0.026 & 0.025 & 0.014 & 0.001 & 0.021 & 0.021 & 0.022 & 0.016 & 0.007 \\
\hline \multicolumn{14}{|l|}{ Southern Africa } \\
\hline & Botswana & 1964 & 1971 & 0.006 & 0.017 & 0.015 & 0.006 & 0.001 & 0.008 & 0.012 & 0.007 & 0.003 & 0.001 \\
\hline & Botswana & 1971 & 1981 & 0.005 & 0.034 & 0.007 & -0.001 & -0.001 & 0.007 & 0.014 & 0.002 & 0.000 & -0.001 \\
\hline & Botswana & 1981 & 1991 & 0.033 & 0.079 & 0.041 & 0.025 & 0.022 & 0.042 & 0.069 & 0.043 & 0.034 & 0.030 \\
\hline & Namibia & 1991 & 2001 & 0.007 & 0.031 & 0.008 & -0.004 & -0.002 & 0.009 & 0.027 & 0.005 & 0.000 & -0.001 \\
\hline & South Africa & 1951 & 1960 & 0.012 & 0.045 & -0.001 & -0.003 & -0.005 & 0.011 & 0.016 & 0.006 & 0.006 & 0.002 \\
\hline & South Africa & 1960 & 1970 & 0.008 & 0.043 & -0.002 & -0.004 & -0.021 & 0.005 & 0.011 & 0.002 & 0.000 & -0.008 \\
\hline & South Africa & 1970 & 1996 & 0.009 & 0.027 & -0.012 & -0.010 & 0.000 & 0.006 & 0.023 & 0.015 & -0.001 & -0.004 \\
\hline & Swaziland & 1986 & 1997 & 0.001 & 0.019 & -0.009 & -0.015 & -0.005 & 0.003 & 0.009 & -0.003 & -0.004 & -0.002 \\
\hline \multicolumn{14}{|l|}{ Western Africa } \\
\hline & Benin & 1992 & 2002 & 0.008 & 0.011 & 0.003 & 0.000 & -0.002 & 0.010 & 0.001 & 0.004 & 0.002 & -0.002 \\
\hline & Burkina Faso & 1975 & 1985 & 0.006 & 0.012 & 0.007 & 0.002 & 0.002 & 0.006 & 0.006 & 0.003 & 0.003 & 0.005 \\
\hline & Cape Verde & 1990 & 2000 & 0.019 & 0.032 & 0.025 & 0.008 & 0.008 & 0.021 & 0.028 & 0.019 & 0.011 & 0.009 \\
\hline & Cote d Ivoire & 1975 & 1988 & 0.012 & 0.007 & -0.001 & -0.003 & -0.002 & 0.014 & 0.004 & 0.000 & 0.001 & 0.000 \\
\hline & Ghana & 1960 & 1970 & 0.007 & 0.016 & 0.000 & 0.000 & -0.001 & 0.010 & 0.006 & 0.003 & 0.003 & 0.002 \\
\hline & Ghana & 1970 & 1984 & 0.005 & 0.005 & -0.004 & 0.002 & -0.001 & 0.006 & 0.001 & 0.002 & 0.003 & 0.003 \\
\hline & Ghana & 1984 & 2000 & 0.013 & 0.024 & 0.011 & 0.005 & 0.018 & 0.017 & 0.016 & 0.011 & 0.010 & 0.013 \\
\hline & Liberia & 1974 & 1984 & 0.015 & 0.027 & 0.002 & -0.003 & -0.003 & 0.017 & 0.015 & -0.001 & 0.002 & 0.000 \\
\hline & Mali & 1976 & 1987 & 0.006 & 0.008 & 0.006 & 0.002 & 0.002 & 0.007 & 0.005 & 0.004 & 0.003 & 0.002 \\
\hline & Niger & 1977 & 1988 & 0.004 & 0.004 & 0.002 & -0.001 & -0.002 & 0.003 & 0.002 & 0.001 & -0.001 & -0.001 \\
\hline & Niger & 1988 & 2001 & 0.003 & 0.000 & 0.001 & 0.001 & 0.000 & 0.003 & 0.000 & 0.001 & 0.003 & 0.003 \\
\hline & Senegal & 1976 & 1988 & 0.006 & 0.012 & 0.007 & -0.002 & -0.004 & 0.006 & 0.003 & 0.006 & 0.003 & -0.002 \\
\hline & Togo & 1959 & 1970 & 0.004 & 0.005 & 0.001 & 0.001 & 0.000 & 0.005 & 0.001 & 0.001 & 0.001 & 0.000 \\
\hline \multicolumn{14}{|l|}{ Central Africa } \\
\hline & Cameroon & 1976 & 1987 & 0.015 & 0.028 & 0.001 & -0.002 & -0.001 & 0.013 & 0.014 & 0.001 & 0.001 & 0.002 \\
\hline & Mean(Africa) & & & 0.009 & 0.019 & 0.007 & 0.002 & 0.001 & 0.011 & 0.012 & 0.007 & 0.005 & 0.003 \\
\hline & Median(Africa) & & & 0.006 & 0.015 & 0.003 & 0.000 & -0.001 & 0.007 & 0.009 & 0.003 & 0.003 & 0.001 \\
\hline
\end{tabular}




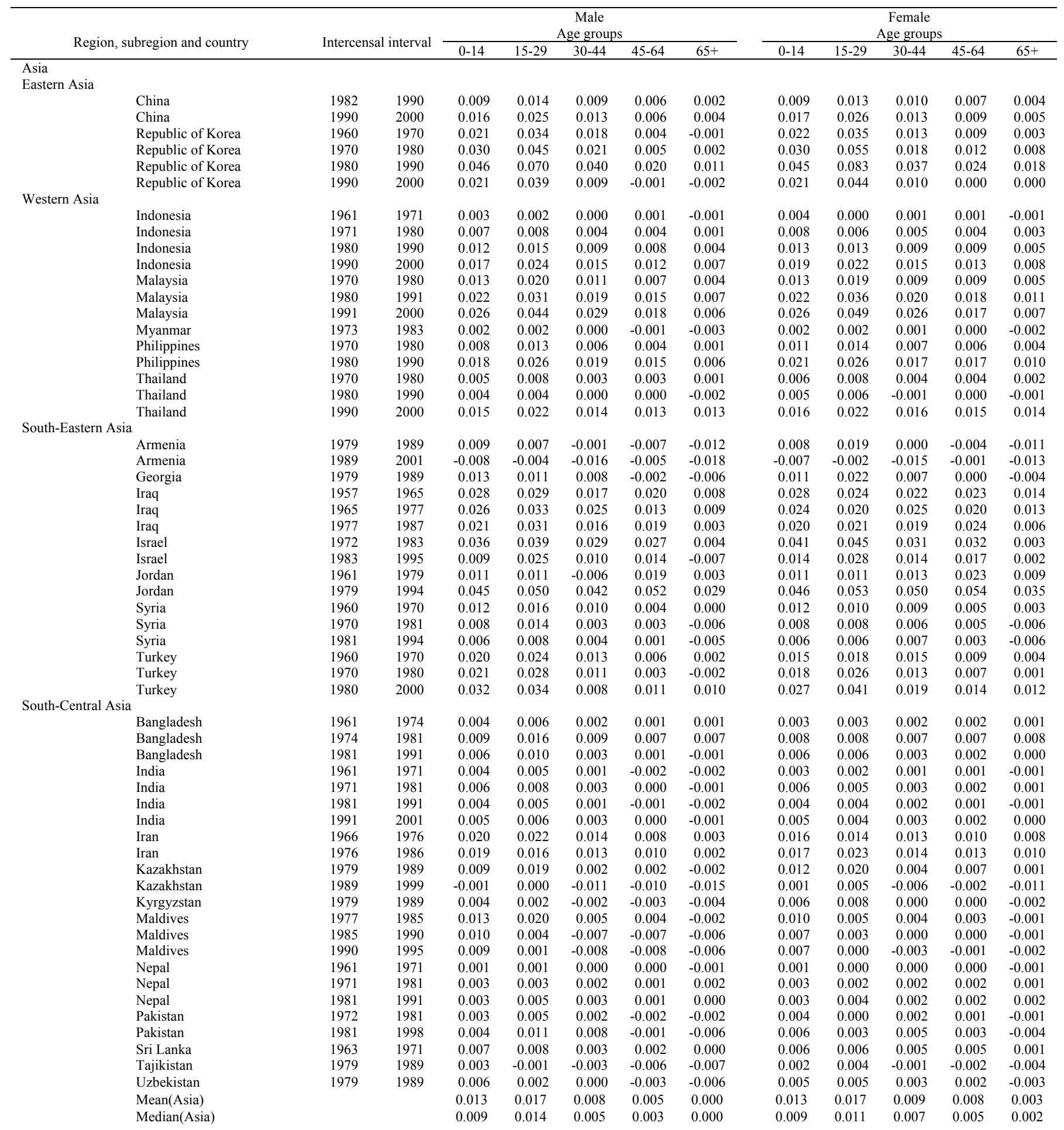




\begin{tabular}{|c|c|c|c|c|c|c|c|c|c|c|c|c|}
\hline \multirow{2}{*}{ Region, subregion and country } & \multirow{2}{*}{\multicolumn{2}{|c|}{ Intercensal interval }} & \multicolumn{5}{|c|}{$\begin{array}{c}\text { Male } \\
\text { Age groups } \\
\end{array}$} & \multicolumn{5}{|c|}{$\begin{array}{c}\text { Female } \\
\text { Age groups } \\
\end{array}$} \\
\hline & & & $0-14$ & $15-29$ & $30-44$ & $45-64$ & $65+$ & $0-14$ & $15-29$ & $30-44$ & $45-64$ & $65+$ \\
\hline \multicolumn{13}{|l|}{ LAC } \\
\hline \multicolumn{13}{|l|}{ Central America and Caribbean } \\
\hline Costa Rica & 1963 & 1973 & 0.010 & 0.015 & 0.010 & 0.012 & 0.002 & 0.014 & 0.016 & 0.012 & 0.015 & 0.014 \\
\hline Costa Rica & 1973 & 1984 & 0.006 & 0.008 & 0.006 & 0.006 & 0.001 & 0.009 & 0.009 & 0.006 & 0.009 & 0.002 \\
\hline Cuba & 1953 & 1970 & 0.009 & 0.016 & 0.003 & -0.005 & -0.008 & 0.011 & 0.017 & -0.001 & 0.000 & -0.004 \\
\hline Cuba & 1970 & 1981 & 0.024 & 0.029 & 0.025 & 0.015 & 0.004 & 0.026 & 0.036 & 0.027 & 0.022 & 0.009 \\
\hline Dominican Republic & 1950 & 1960 & 0.008 & 0.013 & 0.005 & 0.003 & 0.001 & 0.013 & 0.015 & 0.009 & 0.006 & 0.004 \\
\hline Dominican Republic & 1960 & 1970 & 0.013 & 0.020 & 0.011 & 0.009 & 0.006 & 0.019 & 0.021 & 0.011 & 0.012 & 0.007 \\
\hline Dominican Republic & 1970 & 1981 & 0.021 & 0.030 & 0.011 & 0.012 & 0.005 & 0.026 & 0.032 & 0.016 & 0.017 & 0.009 \\
\hline Dominican Republic & 1993 & 2002 & 0.019 & 0.027 & 0.015 & 0.012 & 0.008 & 0.023 & 0.025 & 0.017 & 0.019 & 0.015 \\
\hline El Salvador & 1961 & 1971 & 0.005 & 0.006 & 0.001 & 0.003 & 0.000 & 0.008 & 0.006 & 0.002 & 0.006 & 0.002 \\
\hline El Salvador & 1971 & 1992 & 0.011 & 0.015 & 0.015 & 0.007 & 0.001 & 0.014 & 0.016 & 0.014 & 0.007 & -0.001 \\
\hline Guatemala & 1950 & 1964 & 0.010 & 0.009 & 0.008 & 0.009 & 0.006 & 0.013 & 0.011 & 0.010 & 0.012 & 0.006 \\
\hline Guatemala & 1964 & 1973 & 0.006 & 0.007 & 0.003 & 0.002 & -0.002 & 0.009 & 0.007 & 0.005 & 0.005 & 0.000 \\
\hline Haiti & 1950 & 1971 & 0.006 & 0.005 & 0.000 & -0.001 & -0.001 & 0.011 & 0.006 & 0.001 & 0.000 & -0.002 \\
\hline Haiti & 1971 & 1982 & 0.001 & 0.005 & -0.004 & -0.003 & -0.004 & 0.006 & -0.001 & -0.005 & -0.003 & -0.005 \\
\hline Honduras & 1961 & 1974 & 0.009 & 0.013 & 0.005 & 0.003 & 0.003 & 0.013 & 0.013 & 0.007 & 0.007 & 0.003 \\
\hline Honduras & 1974 & 1988 & 0.010 & 0.012 & 0.007 & 0.006 & 0.008 & 0.014 & 0.017 & 0.009 & 0.009 & 0.009 \\
\hline Jamaica & 1960 & 1982 & 0.016 & 0.029 & 0.001 & 0.004 & 0.002 & 0.020 & 0.033 & 0.002 & 0.002 & 0.006 \\
\hline Jamaica & 1982 & 1991 & 0.004 & 0.010 & -0.008 & -0.006 & -0.005 & 0.006 & 0.014 & -0.009 & -0.004 & -0.004 \\
\hline Jamaica & 1991 & 2001 & 0.004 & 0.007 & -0.002 & -0.002 & -0.001 & 0.006 & 0.010 & -0.003 & 0.000 & 0.000 \\
\hline Mexico & 1960 & 1970 & 0.018 & 0.023 & 0.019 & 0.011 & 0.001 & 0.021 & 0.023 & 0.020 & 0.015 & 0.005 \\
\hline Mexico & 1970 & 1980 & 0.019 & 0.030 & 0.017 & 0.010 & 0.002 & 0.023 & 0.031 & 0.020 & 0.017 & 0.008 \\
\hline Mexico & 1980 & 1990 & 0.017 & 0.030 & 0.016 & 0.009 & 0.002 & 0.019 & 0.030 & 0.015 & 0.012 & 0.001 \\
\hline Mexico & 1990 & 2000 & 0.014 & 0.028 & 0.010 & 0.002 & -0.006 & 0.015 & 0.026 & 0.010 & 0.006 & -0.005 \\
\hline Nicaragua & 1963 & 1971 & 0.013 & 0.013 & 0.013 & 0.009 & 0.005 & 0.020 & 0.016 & 0.016 & 0.017 & 0.009 \\
\hline Panama & 1960 & 1970 & 0.013 & 0.020 & 0.010 & 0.004 & -0.005 & 0.020 & 0.021 & 0.011 & 0.009 & 0.004 \\
\hline Panama & 1970 & 1980 & 0.008 & 0.014 & 0.001 & -0.001 & -0.004 & 0.014 & 0.013 & 0.004 & 0.004 & -0.003 \\
\hline Panama & 1980 & 1990 & 0.010 & 0.014 & 0.004 & 0.002 & -0.002 & 0.014 & 0.016 & 0.009 & 0.005 & 0.003 \\
\hline Puerto Rico & 1960 & 1970 & 0.024 & 0.038 & 0.031 & 0.022 & 0.014 & 0.026 & 0.037 & 0.032 & 0.028 & 0.022 \\
\hline Puerto Rico & 1970 & 1980 & 0.023 & 0.026 & 0.016 & 0.017 & 0.012 & 0.024 & 0.031 & 0.022 & 0.022 & 0.015 \\
\hline Puerto Rico & 1980 & 1990 & 0.015 & 0.016 & 0.011 & 0.008 & 0.003 & 0.016 & 0.020 & 0.014 & 0.012 & 0.006 \\
\hline South America & 1960 & 1980 & 0.030 & 0.052 & 0.009 & 0.006 & -0.004 & 0.037 & \multicolumn{3}{|c|}{ South America } & 0.005 \\
\hline Argentina & 1980 & 1991 & 0.029 & 0.038 & 0.025 & 0.017 & 0.000 & 0.036 & 0.046 & 0.032 & 0.030 & 0.006 \\
\hline Bolivia & 1976 & 1992 & 0.024 & 0.022 & 0.021 & 0.009 & 0.005 & 0.029 & 0.028 & 0.021 & 0.010 & 0.005 \\
\hline Brazil & 1960 & 1970 & 0.023 & 0.030 & 0.024 & 0.018 & 0.008 & 0.027 & 0.033 & 0.026 & 0.025 & 0.013 \\
\hline Brazil & 1970 & 1980 & 0.030 & 0.045 & 0.030 & 0.022 & 0.009 & 0.035 & 0.047 & 0.032 & 0.031 & 0.017 \\
\hline Brazil & 1980 & 1991 & 0.026 & 0.036 & 0.023 & 0.015 & 0.006 & 0.032 & 0.043 & 0.027 & 0.023 & 0.012 \\
\hline Brazil & 1991 & 2000 & 0.029 & 0.041 & 0.026 & 0.014 & 0.008 & 0.034 & 0.048 & 0.031 & 0.024 & 0.017 \\
\hline Chile & 1960 & 1970 & 0.024 & 0.037 & 0.021 & 0.009 & 0.009 & 0.032 & 0.044 & 0.019 & 0.017 & 0.009 \\
\hline Chile & 1970 & 1982 & 0.027 & 0.034 & 0.019 & 0.015 & 0.006 & 0.036 & 0.046 & 0.023 & 0.024 & 0.014 \\
\hline Chile & 1982 & 1992 & 0.008 & 0.012 & 0.000 & -0.006 & -0.011 & 0.015 & 0.015 & 0.000 & -0.002 & -0.006 \\
\hline Chile & 1992 & 2002 & 0.020 & 0.031 & 0.016 & 0.007 & 0.001 & 0.026 & 0.029 & 0.016 & 0.008 & 0.005 \\
\hline Colombia & 1950 & 1964 & 0.016 & 0.020 & 0.012 & 0.008 & 0.004 & 0.024 & 0.020 & 0.013 & 0.014 & 0.001 \\
\hline Colombia & 1964 & 1973 & 0.008 & 0.005 & 0.002 & 0.003 & 0.000 & 0.017 & 0.011 & 0.008 & 0.006 & 0.008 \\
\hline Colombia & 1985 & 1993 & 0.012 & 0.027 & 0.011 & 0.009 & 0.004 & 0.021 & 0.030 & 0.011 & 0.015 & 0.007 \\
\hline Ecuador & 1962 & 1974 & 0.009 & 0.011 & 0.006 & 0.003 & 0.000 & 0.013 & 0.012 & 0.007 & 0.005 & 0.000 \\
\hline Ecuador & 1974 & 1982 & 0.017 & 0.027 & 0.013 & 0.010 & 0.003 & 0.021 & 0.025 & 0.012 & 0.011 & 0.004 \\
\hline Ecuador & 1982 & 1990 & 0.015 & 0.024 & 0.010 & 0.010 & 0.006 & 0.020 & 0.027 & 0.010 & 0.012 & 0.009 \\
\hline Ecuador & 1990 & 2001 & 0.013 & 0.024 & 0.008 & 0.009 & 0.014 & 0.016 & 0.021 & 0.007 & 0.011 & 0.012 \\
\hline Paraguay & 1962 & 1972 & 0.008 & 0.000 & 0.005 & 0.003 & 0.000 & 0.010 & 0.005 & 0.005 & 0.006 & 0.000 \\
\hline Paraguay & 1972 & 1982 & 0.013 & 0.012 & 0.011 & 0.008 & 0.003 & 0.015 & 0.015 & 0.010 & 0.010 & 0.003 \\
\hline Paraguay & 1982 & 1992 & 0.016 & 0.019 & 0.013 & 0.007 & 0.002 & 0.021 & 0.027 & 0.014 & 0.013 & 0.008 \\
\hline Paraguay & 1992 & 2002 & 0.013 & 0.022 & 0.011 & 0.006 & -0.001 & 0.019 & 0.027 & 0.011 & 0.010 & 0.003 \\
\hline Peru & 1961 & 1972 & 0.027 & 0.032 & 0.018 & 0.013 & 0.007 & 0.030 & 0.029 & 0.019 & 0.016 & 0.009 \\
\hline Peru & 1972 & 1981 & 0.020 & 0.026 & 0.012 & 0.010 & 0.004 & 0.023 & 0.025 & 0.013 & 0.011 & 0.005 \\
\hline Peru & 1981 & 1993 & 0.018 & 0.020 & 0.009 & 0.008 & 0.006 & 0.022 & 0.024 & 0.013 & 0.012 & 0.008 \\
\hline Uruguay & 1963 & 1975 & 0.004 & 0.001 & -0.007 & -0.004 & -0.006 & 0.013 & 0.010 & 0.003 & 0.010 & -0.003 \\
\hline Uruguay & 1975 & 1985 & 0.022 & 0.021 & 0.020 & 0.014 & 0.009 & 0.037 & 0.036 & 0.031 & 0.032 & 0.020 \\
\hline Uruguay & 1985 & 1996 & 0.023 & 0.029 & 0.030 & 0.021 & 0.007 & 0.035 & 0.032 & 0.030 & 0.029 & 0.015 \\
\hline Venezuela & 1961 & 1971 & 0.020 & 0.032 & 0.001 & -0.002 & -0.001 & 0.029 & 0.034 & 0.013 & 0.012 & -0.001 \\
\hline Venezuela & 1971 & 1981 & 0.028 & 0.047 & 0.024 & 0.015 & 0.013 & 0.035 & 0.048 & 0.027 & 0.024 & 0.016 \\
\hline Venezuela & 1981 & 1990 & 0.026 & 0.035 & 0.014 & 0.008 & 0.008 & 0.033 & 0.046 & 0.023 & 0.022 & 0.017 \\
\hline Mean(LAC) & & & 0.016 & 0.022 & 0.012 & 0.008 & 0.003 & 0.021 & 0.025 & 0.013 & 0.013 & 0.006 \\
\hline Median(LAC) & & & 0.015 & 0.022 & 0.011 & 0.008 & 0.003 & 0.020 & 0.025 & 0.012 & 0.012 & 0.006 \\
\hline
\end{tabular}


Male

Region and Total
Mean(Africa)
Mean(Asia)
Mean(LAC)
Mean Total
Median(Africa)
Median(Asia)
Median(LAC)
Median Total

Age groups

\begin{tabular}{|c|c|c|c|c|c|c|c|c|c|}
\hline \multicolumn{5}{|c|}{ Age groups } & \multicolumn{5}{|c|}{ Age groups } \\
\hline $0-14$ & $15-29$ & $30-44$ & $45-64$ & $65+$ & $0-14$ & $15-29$ & $30-44$ & $45-64$ & $65+$ \\
\hline 0.009 & 0.019 & 0.007 & 0.002 & 0.001 & 0.011 & 0.012 & 0.007 & 0.005 & 0.003 \\
\hline 0.013 & 0.017 & 0.008 & 0.005 & 0.000 & 0.013 & 0.017 & 0.009 & 0.008 & 0.003 \\
\hline 0.016 & 0.022 & 0.012 & 0.008 & 0.003 & 0.021 & 0.025 & 0.013 & 0.013 & 0.006 \\
\hline 0.013 & 0.019 & 0.009 & 0.005 & 0.001 & 0.015 & 0.018 & 0.010 & 0.009 & 0.004 \\
\hline 0.006 & 0.015 & 0.003 & 0.000 & -0.001 & 0.007 & 0.009 & 0.003 & 0.003 & 0.001 \\
\hline 0.009 & 0.014 & 0.005 & 0.003 & 0.000 & 0.009 & 0.011 & 0.007 & 0.005 & 0.002 \\
\hline 0.015 & 0.022 & 0.011 & 0.008 & 0.003 & 0.020 & 0.025 & 0.012 & 0.012 & 0.006 \\
\hline 0.010 & 0.016 & 0.007 & 0.004 & 0.001 & 0.013 & 0.015 & 0.007 & 0.006 & 0.003 \\
\hline
\end{tabular}


Table A3. Age-specific net in-migration rates to urban areas by sex and age groups

\begin{tabular}{|c|c|c|c|c|c|c|c|c|c|c|c|c|}
\hline \multirow{2}{*}{ Region, subregion and country } & \multirow{2}{*}{\multicolumn{2}{|c|}{ Intercensal interval }} & \multicolumn{5}{|c|}{$\begin{array}{c}\text { Male } \\
\text { Age groups }\end{array}$} & \multicolumn{5}{|c|}{$\begin{array}{c}\text { Female } \\
\text { Age groups }\end{array}$} \\
\hline & & & $0-14$ & $15-29$ & $30-44$ & $45-64$ & $65+$ & $0-14$ & $15-29$ & $30-44$ & $45-64$ & $65+$ \\
\hline \multicolumn{13}{|l|}{ Africa } \\
\hline \multicolumn{13}{|l|}{ Eastern Africa } \\
\hline Ethiopia & 1984 & 1994 & 0.023 & 0.033 & 0.009 & 0.014 & 0.015 & 0.035 & 0.007 & 0.002 & 0.028 & 0.023 \\
\hline \multirow[t]{2}{*}{ Kenya } & 1969 & 1979 & 0.044 & 0.086 & 0.009 & -0.005 & 0.020 & 0.051 & 0.057 & 0.015 & 0.031 & 0.048 \\
\hline & 1979 & 1989 & 0.003 & 0.062 & -0.009 & -0.036 & -0.050 & 0.010 & 0.032 & -0.021 & -0.030 & -0.037 \\
\hline Madagascar & 1975 & 1993 & 0.022 & 0.012 & 0.019 & 0.018 & 0.008 & 0.025 & 0.012 & 0.022 & 0.020 & 0.013 \\
\hline \multirow{2}{*}{ Mauritius } & 1972 & 1983 & -0.001 & -0.002 & -0.001 & 0.000 & -0.004 & -0.001 & -0.003 & -0.001 & 0.000 & -0.003 \\
\hline & 1983 & 2000 & 0.004 & -0.004 & 0.004 & 0.000 & 0.000 & 0.004 & -0.002 & 0.003 & 0.000 & -0.001 \\
\hline \multirow[t]{2}{*}{ Rwanda } & 1978 & 1991 & 0.018 & 0.035 & -0.012 & -0.016 & -0.031 & 0.019 & 0.029 & -0.005 & -0.011 & -0.014 \\
\hline & 1991 & 2002 & 0.094 & 0.113 & 0.071 & 0.074 & 0.085 & 0.098 & 0.082 & 0.058 & 0.084 & 0.087 \\
\hline \multirow[t]{2}{*}{ Uganda } & 1969 & 1991 & 0.018 & 0.034 & -0.026 & -0.028 & -0.022 & 0.027 & 0.022 & -0.018 & -0.004 & 0.016 \\
\hline & 1991 & 2002 & 0.010 & 0.037 & -0.024 & -0.024 & 0.001 & 0.019 & 0.015 & -0.024 & -0.004 & 0.012 \\
\hline \multirow[t]{2}{*}{ Tanzania } & 1967 & 1978 & 0.087 & 0.095 & 0.050 & 0.040 & 0.062 & 0.088 & 0.078 & 0.057 & 0.069 & 0.073 \\
\hline & 1978 & 1988 & 0.032 & 0.041 & 0.006 & 0.009 & 0.009 & 0.036 & 0.034 & 0.011 & 0.023 & 0.024 \\
\hline \multirow[t]{2}{*}{ Zambia } & 1974 & 1980 & 0.012 & 0.028 & 0.001 & -0.018 & 0.000 & 0.017 & 0.021 & 0.000 & 0.002 & 0.046 \\
\hline & 1980 & 1990 & -0.003 & 0.008 & -0.007 & -0.035 & -0.031 & 0.000 & 0.002 & -0.017 & -0.030 & -0.019 \\
\hline Zimbabwe & 1969 & 1982 & 0.034 & 0.069 & 0.001 & -0.005 & -0.022 & 0.042 & 0.055 & 0.010 & -0.007 & -0.029 \\
\hline & 1982 & 1992 & 0.025 & 0.065 & 0.009 & -0.008 & -0.045 & 0.036 & 0.049 & 0.008 & -0.011 & -0.022 \\
\hline Northern Africa & & & & & & & & & & & & \\
\hline Egypt & 1960 & 1976 & 0.008 & 0.017 & 0.008 & 0.005 & -0.005 & 0.011 & 0.010 & 0.006 & 0.006 & -0.001 \\
\hline & 1976 & 1986 & 0.002 & 0.005 & 0.001 & 0.000 & -0.013 & 0.005 & 0.001 & 0.000 & 0.000 & -0.010 \\
\hline & 1986 & 1996 & 0.001 & 0.001 & -0.002 & -0.001 & -0.014 & 0.002 & 0.000 & -0.001 & -0.002 & -0.016 \\
\hline Libya & 1964 & 1973 & 0.077 & 0.090 & 0.078 & 0.065 & 0.075 & 0.078 & 0.080 & 0.083 & 0.074 & 0.071 \\
\hline & 1973 & 1984 & 0.020 & 0.021 & 0.011 & 0.015 & 0.021 & 0.020 & 0.020 & 0.019 & 0.025 & 0.023 \\
\hline Morocco & 1960 & 1971 & 0.018 & 0.012 & 0.014 & -0.004 & 0.002 & 0.026 & 0.004 & 0.015 & 0.007 & 0.005 \\
\hline & 1971 & 1982 & 0.021 & 0.032 & 0.018 & 0.007 & -0.005 & 0.023 & 0.016 & 0.016 & 0.008 & 0.001 \\
\hline & 1982 & 1994 & 0.022 & 0.019 & 0.013 & 0.007 & 0.006 & 0.022 & 0.018 & 0.015 & 0.012 & 0.004 \\
\hline & 1994 & 2004 & 0.012 & 0.010 & 0.005 & 0.002 & -0.003 & 0.012 & 0.012 & 0.005 & 0.004 & 0.001 \\
\hline Sudan & 1973 & 1983 & 0.015 & 0.017 & -0.008 & 0.002 & -0.001 & 0.014 & 0.002 & 0.010 & 0.014 & 0.007 \\
\hline Tunisia & 1966 & 1975 & 0.028 & 0.016 & 0.024 & 0.017 & 0.004 & 0.031 & 0.024 & 0.027 & 0.021 & 0.005 \\
\hline & 1975 & 1984 & 0.011 & 0.012 & 0.007 & 0.003 & -0.002 & 0.012 & 0.007 & 0.005 & 0.006 & 0.005 \\
\hline & 1984 & 1994 & 0.018 & 0.018 & 0.014 & 0.010 & 0.001 & 0.018 & 0.015 & 0.013 & 0.011 & 0.004 \\
\hline Southern Africa & & & & & & & & & & & & \\
\hline Botswana & 1964 & 1971 & 0.101 & 0.176 & 0.135 & 0.083 & 0.036 & 0.131 & 0.132 & 0.107 & 0.071 & 0.045 \\
\hline & 1971 & 1981 & 0.047 & 0.105 & 0.020 & -0.003 & -0.018 & 0.056 & 0.060 & 0.012 & -0.006 & -0.017 \\
\hline & 1981 & 1991 & 0.097 & 0.098 & 0.042 & 0.054 & 0.101 & 0.107 & 0.093 & 0.067 & 0.100 & 0.122 \\
\hline Namibia & 1991 & 2001 & 0.024 & 0.056 & 0.008 & -0.008 & -0.012 & 0.030 & 0.048 & 0.007 & -0.001 & -0.004 \\
\hline South Africa & 1951 & 1960 & 0.021 & 0.034 & -0.001 & -0.003 & -0.007 & 0.018 & 0.020 & 0.007 & 0.008 & 0.003 \\
\hline & 1960 & 1970 & 0.012 & 0.029 & -0.001 & -0.003 & -0.028 & 0.008 & 0.012 & 0.002 & 0.000 & -0.010 \\
\hline & 1970 & 1996 & 0.012 & 0.018 & -0.006 & -0.006 & 0.000 & 0.008 & 0.020 & 0.010 & -0.001 & -0.004 \\
\hline Swaziland & 1986 & 1997 & 0.005 & 0.044 & -0.012 & -0.034 & -0.035 & 0.016 & 0.024 & -0.008 & -0.017 & -0.017 \\
\hline Western Africa & & & & & & & & & & & & \\
\hline Benin & 1992 & 2002 & 0.016 & 0.013 & 0.004 & 0.000 & -0.006 & 0.019 & 0.002 & 0.007 & 0.003 & -0.004 \\
\hline Burkina Faso & 1975 & 1985 & 0.056 & 0.079 & 0.050 & 0.027 & 0.035 & 0.053 & 0.050 & 0.037 & 0.042 & 0.062 \\
\hline Cape Verde & 1990 & 2000 & 0.021 & 0.028 & 0.016 & 0.009 & 0.015 & 0.023 & 0.024 & 0.017 & 0.015 & 0.012 \\
\hline Cote d Ivoire & 1975 & 1988 & 0.023 & 0.008 & -0.001 & -0.007 & -0.012 & 0.025 & 0.006 & -0.001 & 0.002 & 0.000 \\
\hline Ghana & 1960 & 1970 & 0.023 & 0.031 & 0.000 & 0.000 & -0.004 & 0.027 & 0.015 & 0.010 & 0.011 & 0.007 \\
\hline & 1970 & 1984 & 0.012 & 0.008 & -0.007 & 0.004 & -0.002 & 0.014 & 0.002 & 0.004 & 0.009 & 0.008 \\
\hline & 1984 & 2000 & 0.023 & 0.029 & 0.013 & 0.008 & 0.036 & 0.029 & 0.019 & 0.015 & 0.016 & 0.022 \\
\hline Liberia & 1974 & 1984 & 0.028 & 0.034 & 0.003 & -0.008 & -0.017 & 0.030 & 0.022 & -0.003 & 0.010 & 0.002 \\
\hline Mali & 1976 & 1987 & 0.023 & 0.028 & 0.022 & 0.012 & 0.010 & 0.027 & 0.017 & 0.016 & 0.014 & 0.012 \\
\hline Niger & 1977 & 1988 & 0.023 & 0.019 & 0.013 & -0.004 & -0.018 & 0.015 & 0.009 & 0.004 & -0.010 & -0.010 \\
\hline & 1988 & 2001 & 0.015 & -0.001 & 0.003 & 0.006 & -0.001 & 0.014 & -0.001 & 0.005 & 0.014 & 0.020 \\
\hline Senegal & 1976 & 1988 & 0.011 & 0.017 & 0.011 & -0.004 & -0.010 & 0.011 & 0.005 & 0.010 & 0.005 & -0.005 \\
\hline Togo & 1959 & 1970 & 0.036 & 0.023 & 0.005 & 0.007 & 0.003 & 0.035 & 0.004 & 0.006 & 0.013 & 0.003 \\
\hline Central Africa & & & & & & & & & & & & \\
\hline Cameroon & 1976 & 1987 & 0.031 & 0.031 & 0.002 & -0.006 & -0.003 & 0.027 & 0.022 & 0.003 & 0.004 & 0.010 \\
\hline Mean(Africa) & & & 0.026 & 0.037 & 0.012 & 0.005 & 0.002 & 0.029 & 0.026 & 0.013 & 0.013 & 0.011 \\
\hline Median(Africa) & & & 0.021 & 0.028 & 0.006 & 0.000 & -0.002 & 0.023 & 0.018 & 0.007 & 0.007 & 0.004 \\
\hline
\end{tabular}




\begin{tabular}{|c|c|c|c|c|c|c|c|c|c|c|c|c|}
\hline \multirow{2}{*}{ Region, subregion and country } & \multirow{2}{*}{\multicolumn{2}{|c|}{ Intercensal interval }} & \multicolumn{5}{|c|}{$\begin{array}{c}\text { Male } \\
\text { Age groups }\end{array}$} & \multicolumn{5}{|c|}{$\begin{array}{c}\text { Female } \\
\text { Age groups }\end{array}$} \\
\hline & & & $0-14$ & $15-29$ & $30-44$ & $45-64$ & $65+$ & $0-14$ & $15-29$ & $30-44$ & $45-64$ & $65+$ \\
\hline \multicolumn{13}{|l|}{ Asia } \\
\hline \multicolumn{13}{|l|}{ Eastern Asia } \\
\hline \multirow[t]{2}{*}{ China } & 1982 & 1990 & 0.040 & 0.043 & 0.023 & 0.017 & 0.008 & 0.040 & 0.042 & 0.027 & 0.022 & 0.014 \\
\hline & 1990 & 2000 & 0.046 & 0.048 & 0.022 & 0.013 & 0.010 & 0.049 & 0.051 & 0.023 & 0.018 & 0.012 \\
\hline \multirow[t]{4}{*}{ Republic of Korea } & 1960 & 1970 & 0.044 & 0.049 & 0.028 & 0.008 & -0.005 & 0.046 & 0.046 & 0.022 & 0.022 & 0.010 \\
\hline & 1970 & 1980 & 0.035 & 0.034 & 0.017 & 0.007 & 0.005 & 0.036 & 0.035 & 0.016 & 0.018 & 0.015 \\
\hline & 1980 & 1990 & 0.025 & 0.031 & 0.015 & 0.014 & 0.015 & 0.025 & 0.030 & 0.014 & 0.018 & 0.018 \\
\hline & 1990 & 2000 & 0.006 & 0.011 & 0.002 & 0.000 & -0.002 & 0.006 & 0.010 & 0.002 & 0.000 & 0.000 \\
\hline \multicolumn{13}{|l|}{ Western Asia } \\
\hline Indonesia & 1961 & 1971 & 0.019 & 0.009 & 0.002 & 0.003 & -0.009 & 0.022 & 0.001 & 0.006 & 0.006 & -0.003 \\
\hline & 1971 & 1980 & 0.032 & 0.026 & 0.018 & 0.017 & 0.006 & 0.036 & 0.020 & 0.023 & 0.020 & 0.013 \\
\hline & 1980 & 1990 & 0.035 & 0.033 & 0.022 & 0.024 & 0.015 & 0.040 & 0.030 & 0.024 & 0.027 & 0.015 \\
\hline & 1990 & 2000 & 0.035 & 0.034 & 0.024 & 0.023 & 0.016 & 0.038 & 0.031 & 0.025 & 0.025 & 0.017 \\
\hline Malaysia & 1970 & 1980 & 0.031 & 0.033 & 0.019 & 0.014 & 0.008 & 0.032 & 0.032 & 0.017 & 0.019 & 0.009 \\
\hline & 1980 & 1991 & 0.031 & 0.032 & 0.018 & 0.019 & 0.010 & 0.032 & 0.036 & 0.020 & 0.023 & 0.014 \\
\hline & 1991 & 2000 & 0.024 & 0.030 & 0.018 & 0.014 & 0.006 & 0.024 & 0.031 & 0.016 & 0.014 & 0.007 \\
\hline Myanmar & 1973 & 1983 & 0.007 & 0.005 & -0.001 & -0.004 & -0.013 & 0.006 & 0.007 & 0.003 & 0.001 & -0.005 \\
\hline Philippines & 1970 & 1980 & 0.017 & 0.023 & 0.011 & 0.008 & 0.002 & 0.024 & 0.020 & 0.011 & 0.011 & 0.006 \\
\hline & 1980 & 1990 & 0.027 & 0.031 & 0.022 & 0.020 & 0.009 & 0.032 & 0.027 & 0.019 & 0.021 & 0.013 \\
\hline Thailand & 1970 & 1980 & 0.034 & 0.035 & 0.016 & 0.016 & 0.007 & 0.041 & 0.035 & 0.018 & 0.019 & 0.011 \\
\hline & 1980 & 1990 & 0.021 & 0.018 & -0.001 & -0.001 & -0.010 & 0.028 & 0.022 & -0.002 & -0.002 & -0.006 \\
\hline & 1990 & 2000 & 0.058 & 0.060 & 0.037 & 0.039 & 0.041 & 0.062 & 0.054 & 0.040 & 0.045 & 0.043 \\
\hline South-Eastern Asia & & & & & & & & & & & & \\
\hline Armenia & 1979 & 1989 & 0.005 & 0.004 & -0.001 & -0.003 & -0.007 & 0.005 & 0.009 & 0.000 & -0.002 & -0.007 \\
\hline & 1989 & 2001 & -0.005 & -0.002 & -0.008 & -0.002 & -0.011 & -0.004 & -0.001 & -0.006 & -0.001 & -0.008 \\
\hline Georgia & 1979 & 1989 & 0.012 & 0.009 & 0.006 & -0.001 & -0.007 & 0.011 & 0.017 & 0.004 & 0.000 & -0.005 \\
\hline Iraq & 1957 & 1965 & 0.035 & 0.025 & 0.022 & 0.025 & 0.014 & 0.035 & 0.026 & 0.031 & 0.030 & 0.020 \\
\hline & 1965 & 1977 & 0.019 & 0.016 & 0.015 & 0.010 & 0.008 & 0.017 & 0.012 & 0.018 & 0.015 & 0.011 \\
\hline & 1977 & 1987 & 0.012 & 0.012 & 0.006 & 0.009 & 0.002 & 0.011 & 0.009 & 0.009 & 0.012 & 0.003 \\
\hline Israel & 1972 & 1983 & 0.006 & 0.006 & 0.004 & 0.003 & 0.000 & 0.007 & 0.006 & 0.004 & 0.003 & 0.000 \\
\hline & 1983 & 1995 & 0.001 & 0.003 & 0.001 & 0.001 & -0.001 & 0.002 & 0.003 & 0.001 & 0.001 & 0.000 \\
\hline Jordan & 1961 & 1979 & 0.009 & 0.006 & -0.004 & 0.016 & 0.004 & 0.008 & 0.008 & 0.010 & 0.018 & 0.008 \\
\hline & 1979 & 1994 & 0.019 & 0.017 & 0.013 & 0.017 & 0.014 & 0.019 & 0.017 & 0.016 & 0.018 & 0.014 \\
\hline Syria & 1960 & 1970 & 0.019 & 0.019 & 0.012 & 0.006 & 0.000 & 0.017 & 0.014 & 0.013 & 0.008 & 0.005 \\
\hline & 1970 & 1981 & 0.010 & 0.014 & 0.003 & 0.004 & -0.010 & 0.010 & 0.008 & 0.006 & 0.006 & -0.008 \\
\hline Syria & 1981 & 1994 & 0.007 & 0.008 & 0.003 & 0.001 & -0.007 & 0.007 & 0.006 & 0.006 & 0.003 & -0.007 \\
\hline Turkey & 1960 & 1970 & 0.053 & 0.032 & 0.021 & 0.013 & 0.004 & 0.043 & 0.037 & 0.030 & 0.020 & 0.009 \\
\hline & 1970 & 1980 & 0.035 & 0.027 & 0.012 & 0.005 & -0.005 & 0.032 & 0.035 & 0.018 & 0.012 & 0.002 \\
\hline & 1980 & 2000 & 0.025 & 0.017 & 0.004 & 0.008 & 0.010 & 0.021 & 0.024 & 0.011 & 0.010 & 0.011 \\
\hline South-Central Asia & & & & & & & & & & & & \\
\hline Bangladesh & 1961 & 1974 & 0.050 & 0.043 & 0.022 & 0.018 & 0.018 & 0.047 & 0.033 & 0.029 & 0.026 & 0.026 \\
\hline & 1974 & 1981 & 0.075 & 0.081 & 0.053 & 0.056 & 0.068 & 0.072 & 0.060 & 0.060 & 0.072 & 0.074 \\
\hline & 1981 & 1991 & 0.033 & 0.034 & 0.011 & 0.003 & -0.008 & 0.034 & 0.027 & 0.017 & 0.014 & 0.002 \\
\hline India & 1961 & 1971 & 0.017 & 0.016 & 0.003 & -0.007 & -0.012 & 0.016 & 0.010 & 0.004 & 0.003 & -0.007 \\
\hline & 1971 & 1981 & 0.023 & 0.022 & 0.010 & 0.001 & -0.004 & 0.022 & 0.017 & 0.011 & 0.010 & 0.002 \\
\hline & 1981 & 1991 & 0.014 & 0.011 & 0.004 & -0.005 & -0.007 & 0.015 & 0.010 & 0.005 & 0.004 & -0.004 \\
\hline & 1991 & 2001 & 0.015 & 0.015 & 0.007 & 0.000 & -0.003 & 0.016 & 0.010 & 0.007 & 0.006 & 0.001 \\
\hline Iran & 1966 & 1976 & 0.030 & 0.020 & 0.017 & 0.011 & 0.004 & 0.023 & 0.016 & 0.017 & 0.013 & 0.011 \\
\hline & 1976 & 1986 & 0.020 & 0.012 & 0.010 & 0.010 & 0.002 & 0.019 & 0.019 & 0.012 & 0.013 & 0.010 \\
\hline Kazakhstan & 1979 & 1989 & 0.010 & 0.015 & 0.001 & 0.001 & -0.001 & 0.013 & 0.013 & 0.002 & 0.005 & 0.001 \\
\hline & 1989 & 1999 & -0.001 & 0.000 & -0.007 & -0.007 & -0.010 & 0.001 & 0.004 & -0.004 & -0.002 & -0.006 \\
\hline & 1979 & 1989 & 0.009 & 0.003 & -0.002 & -0.004 & -0.007 & 0.014 & 0.010 & 0.000 & -0.001 & -0.003 \\
\hline Maldives & 1977 & 1985 & 0.057 & 0.037 & 0.011 & 0.016 & -0.013 & 0.042 & 0.016 & 0.016 & 0.014 & -0.004 \\
\hline & 1985 & 1990 & 0.037 & 0.006 & -0.013 & -0.024 & -0.031 & 0.026 & 0.007 & 0.001 & -0.001 & -0.002 \\
\hline & 1990 & 1995 & 0.034 & 0.002 & -0.016 & -0.024 & -0.028 & 0.028 & 0.000 & -0.007 & -0.002 & -0.007 \\
\hline Nepal & 1961 & 1971 & 0.022 & 0.019 & 0.003 & -0.007 & -0.029 & 0.017 & 0.004 & 0.006 & -0.001 & -0.021 \\
\hline & 1971 & 1981 & 0.052 & 0.042 & 0.034 & 0.026 & 0.029 & 0.051 & 0.042 & 0.041 & 0.032 & 0.021 \\
\hline & 1981 & 1991 & 0.042 & 0.046 & 0.029 & 0.016 & 0.006 & 0.041 & 0.038 & 0.027 & 0.028 & 0.027 \\
\hline Pakistan & 1972 & 1981 & 0.009 & 0.011 & 0.005 & -0.005 & -0.007 & 0.012 & 0.000 & 0.004 & 0.002 & -0.004 \\
\hline & 1981 & 1998 & 0.010 & 0.019 & 0.013 & -0.002 & -0.017 & 0.014 & 0.005 & 0.010 & 0.007 & -0.011 \\
\hline Sri Lanka & 1963 & 1971 & 0.028 & 0.026 & 0.010 & 0.008 & -0.002 & 0.025 & 0.021 & 0.020 & 0.017 & 0.004 \\
\hline Tajikistan & 1979 & 1989 & 0.008 & -0.001 & -0.004 & -0.009 & -0.015 & 0.004 & 0.008 & -0.001 & -0.002 & -0.006 \\
\hline Uzbekistan & 1979 & 1989 & 0.011 & 0.003 & 0.001 & -0.003 & -0.009 & 0.009 & 0.007 & 0.003 & 0.002 & -0.004 \\
\hline Mean(Asia) & & & 0.025 & 0.022 & 0.011 & 0.007 & 0.001 & 0.024 & 0.020 & 0.013 & 0.013 & 0.006 \\
\hline Median(Asia) & & & 0.022 & 0.019 & 0.011 & 0.007 & 0.000 & 0.023 & 0.017 & 0.012 & 0.012 & 0.004 \\
\hline
\end{tabular}




\begin{tabular}{|c|c|c|c|c|c|c|c|c|c|c|c|c|}
\hline \multirow{2}{*}{ Region, subregion and country } & \multirow{2}{*}{\multicolumn{2}{|c|}{ Intercensal interval }} & \multicolumn{5}{|c|}{$\begin{array}{c}\text { Male } \\
\text { Age groups }\end{array}$} & \multicolumn{5}{|c|}{$\begin{array}{c}\text { Female } \\
\text { Age groups }\end{array}$} \\
\hline & & & $0-14$ & $15-29$ & $30-44$ & $45-64$ & $65+$ & $0-14$ & $15-29$ & $30-44$ & $45-64$ & $65+$ \\
\hline \multicolumn{13}{|l|}{ LAC } \\
\hline \multicolumn{13}{|l|}{ Central America and Caribbean } \\
\hline \multirow[t]{2}{*}{ Costa Rica } & 1963 & 1973 & 0.021 & 0.025 & 0.016 & 0.019 & 0.002 & 0.027 & 0.020 & 0.015 & 0.016 & 0.013 \\
\hline & 1973 & 1984 & 0.010 & 0.010 & 0.008 & 0.008 & 0.002 & 0.014 & 0.010 & 0.007 & 0.008 & 0.002 \\
\hline \multirow[t]{2}{*}{ Cuba } & 1953 & 1970 & 0.008 & 0.012 & 0.002 & -0.003 & -0.005 & 0.010 & 0.011 & 0.000 & 0.000 & -0.001 \\
\hline & 1970 & 1981 & 0.016 & 0.017 & 0.012 & 0.007 & 0.002 & 0.018 & 0.019 & 0.011 & 0.008 & 0.002 \\
\hline \multirow[t]{4}{*}{ Dominican Republic } & 1950 & 1960 & 0.027 & 0.034 & 0.014 & 0.009 & 0.002 & 0.037 & 0.030 & 0.017 & 0.011 & 0.007 \\
\hline & 1960 & 1970 & 0.028 & 0.036 & 0.020 & 0.020 & 0.015 & 0.037 & 0.028 & 0.016 & 0.018 & 0.010 \\
\hline & 1970 & 1981 & 0.024 & 0.030 & 0.013 & 0.015 & 0.008 & 0.032 & 0.026 & 0.015 & 0.017 & 0.009 \\
\hline & 1993 & 2002 & 0.014 & 0.018 & 0.009 & 0.009 & 0.007 & 0.017 & 0.015 & 0.009 & 0.012 & 0.009 \\
\hline El Salvador & 1961 & 1971 & 0.009 & 0.009 & 0.001 & 0.004 & 0.000 & 0.014 & 0.008 & 0.003 & 0.007 & 0.002 \\
\hline & 1971 & 1992 & 0.015 & 0.015 & 0.015 & 0.008 & 0.001 & 0.019 & 0.014 & 0.012 & 0.006 & -0.001 \\
\hline Guatemala & 1950 & 1964 & 0.025 & 0.021 & 0.017 & 0.019 & 0.012 & 0.031 & 0.022 & 0.018 & 0.020 & 0.009 \\
\hline & 1964 & 1973 & 0.012 & 0.012 & 0.005 & 0.003 & -0.003 & 0.018 & 0.011 & 0.008 & 0.008 & 0.000 \\
\hline Haiti & 1950 & 1971 & 0.029 & 0.024 & -0.001 & -0.007 & -0.006 & 0.050 & 0.019 & 0.006 & 0.002 & -0.009 \\
\hline & 1971 & 1982 & 0.006 & 0.016 & -0.019 & -0.018 & -0.029 & 0.025 & -0.003 & -0.018 & -0.011 & -0.026 \\
\hline Honduras & 1961 & 1974 & 0.027 & 0.029 & 0.014 & 0.009 & 0.007 & 0.035 & 0.025 & 0.016 & 0.015 & 0.006 \\
\hline & 1974 & 1988 & 0.020 & 0.019 & 0.011 & 0.012 & 0.015 & 0.027 & 0.021 & 0.013 & 0.014 & 0.011 \\
\hline Jamaica & 1960 & 1982 & 0.026 & 0.032 & 0.002 & 0.006 & 0.005 & 0.031 & 0.030 & 0.002 & 0.003 & 0.010 \\
\hline & 1982 & 1991 & 0.005 & 0.010 & -0.008 & -0.008 & -0.009 & 0.008 & 0.012 & -0.006 & -0.005 & -0.005 \\
\hline & 1991 & 2001 & 0.004 & 0.007 & -0.002 & -0.002 & -0.001 & 0.006 & 0.008 & -0.002 & 0.000 & 0.000 \\
\hline Mexico & 1960 & 1970 & 0.016 & 0.019 & 0.015 & 0.010 & 0.001 & 0.018 & 0.017 & 0.014 & 0.011 & 0.003 \\
\hline & 1970 & 1980 & 0.013 & 0.016 & 0.010 & 0.006 & 0.001 & 0.015 & 0.015 & 0.010 & 0.009 & 0.004 \\
\hline & 1980 & 1990 & 0.009 & 0.012 & 0.006 & 0.004 & 0.001 & 0.010 & 0.011 & 0.005 & 0.005 & 0.001 \\
\hline & 1990 & 2000 & 0.006 & 0.009 & 0.003 & 0.001 & -0.003 & 0.007 & 0.008 & 0.003 & 0.002 & -0.002 \\
\hline Nicaragua & 1963 & 1971 & 0.019 & 0.019 & 0.018 & 0.013 & 0.007 & 0.026 & 0.016 & 0.017 & 0.016 & 0.006 \\
\hline Panama & 1960 & 1970 & 0.021 & 0.024 & 0.012 & 0.005 & -0.006 & 0.030 & 0.019 & 0.010 & 0.008 & 0.003 \\
\hline & 1970 & 1980 & 0.011 & 0.014 & 0.001 & -0.001 & -0.005 & 0.018 & 0.009 & 0.003 & 0.003 & -0.002 \\
\hline & 1980 & 1990 & 0.012 & 0.012 & 0.004 & 0.002 & -0.002 & 0.016 & 0.011 & 0.006 & 0.004 & 0.002 \\
\hline Puerto Rico & 1960 & 1970 & 0.029 & 0.035 & 0.023 & 0.019 & 0.014 & 0.030 & 0.031 & 0.023 & 0.020 & 0.015 \\
\hline & 1970 & 1980 & 0.016 & 0.016 & 0.008 & 0.010 & 0.008 & 0.017 & 0.018 & 0.010 & 0.011 & 0.007 \\
\hline & 1980 & 1990 & 0.008 & 0.008 & 0.005 & 0.003 & 0.002 & 0.008 & 0.009 & 0.006 & 0.004 & 0.002 \\
\hline South America & & & & & & & & & & & & \\
\hline Argentina & 1960 & 1980 & 0.010 & 0.014 & 0.002 & 0.001 & -0.001 & 0.012 & 0.012 & 0.002 & 0.002 & 0.001 \\
\hline & 1980 & 1991 & 0.006 & 0.007 & 0.004 & 0.003 & 0.000 & 0.008 & 0.007 & 0.004 & 0.004 & 0.001 \\
\hline Bolivia & 1976 & 1992 & 0.024 & 0.016 & 0.018 & 0.010 & 0.008 & 0.028 & 0.018 & 0.017 & 0.011 & 0.007 \\
\hline Brazil & 1960 & 1970 & 0.027 & 0.030 & 0.020 & 0.016 & 0.007 & 0.030 & 0.027 & 0.019 & 0.018 & 0.008 \\
\hline & 1970 & 1980 & 0.023 & 0.026 & 0.016 & 0.013 & 0.006 & 0.025 & 0.023 & 0.015 & 0.014 & 0.007 \\
\hline & 1980 & 1991 & 0.013 & 0.013 & 0.008 & 0.006 & 0.003 & 0.015 & 0.014 & 0.008 & 0.007 & 0.004 \\
\hline & 1991 & 2000 & 0.010 & 0.012 & 0.006 & 0.004 & 0.003 & 0.011 & 0.011 & 0.006 & 0.005 & 0.004 \\
\hline Chile & 1960 & 1970 & 0.011 & 0.015 & 0.008 & 0.004 & 0.005 & 0.014 & 0.013 & 0.006 & 0.005 & 0.003 \\
\hline & 1970 & 1982 & 0.008 & 0.009 & 0.005 & 0.005 & 0.002 & 0.010 & 0.009 & 0.004 & 0.005 & 0.003 \\
\hline & 1982 & 1992 & 0.002 & 0.003 & 0.000 & -0.002 & -0.003 & 0.003 & 0.003 & 0.000 & 0.000 & -0.001 \\
\hline & 1992 & 2002 & 0.004 & 0.006 & 0.003 & 0.002 & 0.000 & 0.005 & 0.004 & 0.002 & 0.001 & 0.001 \\
\hline Colombia & 1950 & 1964 & 0.020 & 0.022 & 0.014 & 0.011 & 0.005 & 0.028 & 0.017 & 0.012 & 0.012 & 0.001 \\
\hline & 1964 & 1973 & 0.009 & 0.005 & 0.002 & 0.003 & 0.000 & 0.016 & 0.007 & 0.006 & 0.004 & 0.005 \\
\hline & 1985 & 1993 & 0.007 & 0.013 & 0.005 & 0.005 & 0.002 & 0.011 & 0.010 & 0.004 & 0.006 & 0.003 \\
\hline Ecuador & 1962 & 1974 & 0.015 & 0.017 & 0.010 & 0.005 & 0.000 & 0.022 & 0.014 & 0.010 & 0.007 & 0.000 \\
\hline & 1974 & 1982 & 0.024 & 0.028 & 0.016 & 0.014 & 0.005 & 0.028 & 0.022 & 0.013 & 0.013 & 0.005 \\
\hline & 1982 & 1990 & 0.017 & 0.020 & 0.008 & 0.011 & 0.007 & 0.021 & 0.019 & 0.008 & 0.011 & 0.009 \\
\hline & 1990 & 2001 & 0.011 & 0.016 & 0.005 & 0.007 & 0.012 & 0.013 & 0.013 & 0.004 & 0.008 & 0.009 \\
\hline Paraguay & 1962 & 1972 & 0.017 & 0.000 & 0.008 & 0.005 & -0.001 & 0.021 & 0.006 & 0.007 & 0.007 & 0.000 \\
\hline & 1972 & 1982 & 0.025 & 0.015 & 0.016 & 0.011 & 0.004 & 0.028 & 0.017 & 0.011 & 0.012 & 0.003 \\
\hline & 1982 & 1992 & 0.024 & 0.020 & 0.013 & 0.008 & 0.003 & 0.029 & 0.023 & 0.011 & 0.012 & 0.006 \\
\hline & 1992 & 2002 & 0.014 & 0.018 & 0.009 & 0.005 & -0.001 & 0.020 & 0.018 & 0.007 & 0.007 & 0.002 \\
\hline Peru & 1961 & 1972 & 0.025 & 0.022 & 0.014 & 0.011 & 0.008 & 0.027 & 0.020 & 0.015 & 0.014 & 0.009 \\
\hline & 1972 & 1981 & 0.014 & 0.012 & 0.007 & 0.006 & 0.003 & 0.016 & 0.012 & 0.007 & 0.007 & 0.004 \\
\hline & 1981 & 1993 & 0.011 & 0.008 & 0.004 & 0.004 & 0.003 & 0.013 & 0.009 & 0.005 & 0.005 & 0.004 \\
\hline Uruguay & 1963 & 1975 & 0.001 & 0.000 & -0.002 & -0.001 & -0.001 & 0.003 & 0.002 & 0.001 & 0.001 & 0.000 \\
\hline & 1975 & 1985 & 0.004 & 0.005 & 0.004 & 0.003 & 0.002 & 0.006 & 0.005 & 0.004 & 0.004 & 0.002 \\
\hline & 1985 & 1996 & 0.003 & 0.004 & 0.005 & 0.004 & 0.001 & 0.004 & 0.003 & 0.003 & 0.003 & 0.001 \\
\hline Venezuela & 1961 & 1971 & 0.010 & 0.012 & 0.000 & -0.001 & -0.001 & 0.013 & 0.010 & 0.005 & 0.005 & 0.000 \\
\hline & 1971 & 1981 & 0.010 & 0.012 & 0.006 & 0.005 & 0.006 & 0.012 & 0.010 & 0.006 & 0.007 & 0.004 \\
\hline & 1981 & 1990 & 0.007 & 0.007 & 0.003 & 0.002 & 0.003 & 0.009 & 0.008 & 0.003 & 0.004 & 0.003 \\
\hline Mean(LAC) & & & 0.015 & 0.016 & 0.008 & 0.006 & 0.002 & 0.019 & 0.014 & 0.008 & 0.008 & 0.003 \\
\hline Median(LAC) & & & 0.013 & 0.015 & 0.008 & 0.005 & 0.002 & 0.017 & 0.013 & 0.007 & 0.007 & 0.003 \\
\hline
\end{tabular}




\begin{tabular}{|c|c|c|c|c|c|c|c|c|c|c|}
\hline \multirow{2}{*}{ Region and Total } & \multicolumn{5}{|c|}{$\begin{array}{c}\text { Male } \\
\text { Age groups }\end{array}$} & \multicolumn{5}{|c|}{$\begin{array}{c}\text { Female } \\
\text { Age groups }\end{array}$} \\
\hline & $0-14$ & $15-29$ & $30-44$ & $45-64$ & $65+$ & $0-14$ & $15-29$ & $30-44$ & $45-64$ & $65+$ \\
\hline Mean(Africa) & 0.026 & 0.037 & 0.012 & 0.005 & 0.002 & 0.029 & 0.026 & 0.013 & 0.013 & 0.011 \\
\hline Mean(Asia) & 0.025 & 0.022 & 0.011 & 0.007 & 0.001 & 0.024 & 0.020 & 0.013 & 0.013 & 0.006 \\
\hline Mean(LAC) & 0.015 & 0.016 & 0.008 & 0.006 & 0.002 & 0.019 & 0.014 & 0.008 & 0.008 & 0.003 \\
\hline Mean Total & 0.022 & 0.024 & 0.010 & 0.006 & 0.002 & 0.024 & 0.020 & 0.011 & 0.011 & 0.007 \\
\hline Median(Africa) & 0.021 & 0.028 & 0.006 & 0.000 & -0.002 & 0.023 & 0.018 & 0.007 & 0.007 & 0.004 \\
\hline Median(Asia) & 0.022 & 0.019 & 0.011 & 0.007 & 0.000 & 0.023 & 0.017 & 0.012 & 0.012 & 0.004 \\
\hline Median(LAC) & 0.013 & 0.015 & 0.008 & 0.005 & 0.002 & 0.017 & 0.013 & 0.007 & 0.007 & 0.003 \\
\hline Median Total & 0.018 & 0.018 & 0.008 & 0.005 & 0.001 & 0.020 & 0.016 & 0.008 & 0.008 & 0.003 \\
\hline
\end{tabular}

